Revista de Derecho de la Pontificia Universidad Católica de Valparaíso XXXV (Valparaíso, Chile, 2010, 20 Semestre)

[pp. $109-145$ ]

\title{
El Derecho penal frente al TERRorismo. HACIA UN MODELO PUNITIVO PARTICULAR Y SOBRE EL TRATAMIENTO DE LA TORTURA*
}

["Criminal Law on Terrorism. Towards a Particular Punitive Model and on the Treatment of Torture"]

\author{
Raúl Carnevali** \\ Universidad de Talca
}

\begin{abstract}
RESUMEN
El terrorismo siempre ha supuesto un desafío para el Derecho penal en cuanto a determinar cuáles son los instrumentos jurídico-penales más idóneos para enfrentarlo. Este trabajo, luego de examinar las distintas posiciones de la doctrina, propone cierta flexibilización del marco garantístico. Asimismo, el terrorismo ha suscitado discusión en relación a la tortura. La cuestión a debatir es si cabe o no su justificación bajo ciertas circunstancias.

Palabras Clave: Terrorismo-Garantías - Tortura - Seguridad.
\end{abstract}

\begin{abstract}
Terrorism has always meant a challenge to Criminal law in terms of determining which legal-criminal instruments are the most adequate to face it. After analyzing the different positions of the doctrine, this work proposes certain flexibilization of the guarantee framework. Likewise, terrorism has caused discussion regarding torture. The issue to be discussed is whether to justify it or not under certain circumstances.

KEYWORDS: Terrorism - Guarantees - Torture - Security.
\end{abstract}

* Este trabajo se realizó durante mi período de investigación postdoctoral en el Departamento de Derecho Penal "Cesare Beccaria” de la Universidad de Milán. Mi estancia fue financiada por Becas Chile y por el Centro de Estudios de Derecho Penal de la Universidad de Talca. Algunas de las materias aquí tratadas fueron expuestas en las VI Jornadas Chilenas de Derecho Penal y Ciencias Penales, organizadas por la Universidad Católica de la Santísima Concepción en noviembre de 2009. Quisiera agradecer al Dr. Francesco Viganò (Universidad de Milán), a la Dra. Tatiana Vargas (Universidad de los Andes) y al Mg. Ignacio Castillo (Universidad de Talca) por sus comentarios y observaciones.

** Doctor en Derecho, profesor asociado de Derecho Penal y director del Centro de Estudios de Derecho Penal de la Universidad de Talca. Dirección postal: Québec 415, Providencia, Santiago, Chile. Dirección electrónica: rcarnevali@utalca.cl 


\section{PresentaCión DEL PROBLEMA}

Aun cuando el terrorismo, en sus diversas manifestaciones, ha estado siempre presente en la historia de la humanidad ${ }^{1}$, hoy adquiere especial relevancia por los medios que puede emplear: catastróficos y de consecuencias inimaginables para la humanidad. De allí la especial atención que debe prestar el Derecho - no sólo el punitivo- a estos fenómenos. Resulta ineludible la discusión entre libertad, seguridad, y la búsqueda del necesario equilibrio. ¿Cómo el Estado debe cumplir con su función de maximizar la protección sin descuidar el respeto a las garantías?2

Quisiera graficar la discusión que en este orden se puede dar a través de una escena de la serie de televisión 24 (sexta temporada). El contexto es el siguiente: Estalla una bomba nuclear en California donde mueren 12.000 personas. Frente al atentado el Presidente de la nación debe adoptar medidas, por lo que reúne a sus asesores. En este contexto, tiene lugar un diálogo entre la Consejera de Seguridad Nacional y el Jefe de Gabinete: La primera dice: $-\_$Crees que soy una liberal de corazón blando predicando sobre las libertades civiles? A lo que el Jefe de Gabinete contesta: -La Constitución es una cosa maravillosa, pero vuelve a los días de los padres fundadores. El

\footnotetext{
${ }^{1}$ Bassiouni, Cherif M., Strumenti giuridici peri il contrasto del terrorismo internazionale: un'analisi di carattere politico, en BAssiouni, Cherif M. (editor), La cooperazione internazionale per la prevenzione e la repressione della criminalitá organizata e del terrorismo (Milano, Giuffrè, 2005), p. 93. Cabe tener presente que en 1934, como consecuencia del asesinato del Rey Alejandro de Yugoslavia y del ministro francés de Asuntos Exteriores, Francia presentó ante la Sociedad de las Naciones una iniciativa para castigar los delitos terroristas. En 1937 se firmó el Convenio para la represión y prevención del terrorismo -cuyo juzgamiento debía corresponder a una Corte penal internacional-, pero jamás entró en vigencia, pues sólo fue ratificado por trece Estados. En aquel entonces, se discutía, teórica y políticamente, si el movimiento anarquista podía o no calificarse como terrorista. Véase: MAnzini, Vincenzo, Tratado de Derecho penal (traducción de Sentís Melendo, Buenos Aires, Ediar, 1948), I, pp. 567-569.

${ }^{2}$ Sobre este punto, el politólogo italiano Angelo Panebianco en una columna publicada el 13 de agosto de 2006 en el Corriere della Sera, se preguntaba qué sucedería si se lograba desbaratar un atentado nuclear mucho más grave que los del 11 de septiembre de 2001 gracias a la confesión de un terrorista envuelto en el ataque, arrestado ilegalmente y luego torturado. ¿Cómo conciliar el Estado de Derecho y la seguridad? Señalaba que el Estado de Derecho es un instrumento imperfecto que sirve para regular las relaciones dentro de la comunidad democrática y en condiciones de normalidad. Pero frente a situaciones que ponen en peligro la seguridad nacional debe aceptarse una "zona gris", que se mueve entre la legalidad y la ilegalidad. Según el autor es la única forma de salvar el Estado de Derecho y la democracia. Ver http: - - www.corriere.it - Primo_Piano - Editoriali - 2006 - 08_Agosto - 13 - PANEBIANCO.shtml (consultado el 10 de mayo de 2010).
} 
arma al alcance de la mano era un mosquete de un solo disparo, que lleva medio minuto cargar y disparar. El que puso la bomba nuclear mató a 12.000 personas en menos tiempo y sin siquiera apuntar. Amo la Constitución, pero no quiero estar detrás cuando estalle la siguiente. Más adelante, el mismo Jefe de Gabinete para justificar las limitaciones a las libertades afirma: -Los enemigos de George Washington usaban capas rojas brillantes y marchaban en línea recta. Los padres fundadores nunca pudieron concebir un enemigo sin Estado, escondido entre nosotros. No apuntando a nuestros soldados, sino a nuestras civilizaciones.

Es cierto que se trata de un ejemplo de ficción -y esperemos continúe siéndolo-, pero lamentablemente la realidad nos dice otra cosa y un hecho como el descrito es perfectamente posible, incluso puede ser peor. En este contexto, la cuestión es si los ordenamientos jurídico-penales deben o no "prepararse" para enfrentar situaciones como las descritas, que traerían consigo graves consecuencias. Si ante amenazas semejantes, que en los tiempos de la Ilustración jamás se pudieron concebir, se debe disponer de instrumentos idóneos para enfrentarlos. Cabe preguntarse entonces, ¿el Derecho penal que podemos llamar "clásico" -o Derecho penal del ciudadano- concebido para una criminalidad "común" puede ser eficiente? Incluso, expuesto en términos más radicales ępuede el Derecho penal en general -llámese Derecho penal del ciudadano o del enemigo- ser un medio idóneo y suficiente para enfrentar estos nuevos riesgos o más bien se debe recurrir a mecanismos esencialmente políticos?

Pues bien, establecido el marco general de la discusión, indicaré cuáles son las dos materias a las que dirigiré mi atención: $i$ ) si es preciso o no introducir reglas penales y procesales que aborden de manera particular estos fenómenos especialmente graves. Esto es, si una maximización tuitiva autoriza a flexibilizar ciertas garantías; ii) si los agentes estatales pueden torturar a sospechosos para salvar la vida de inocentes - caso de las "ticking time bombs"- . Reconozco que tan compleja situación, expuesta en estos términos puede generar un fuerte rechazo, pero son hechos que no sólo ocurren, sino que la propia ciudadanía se pregunta si pueden admitirse bajo ciertas circunstancias. Por tanto, el teórico debe afrontarlos y tomar una postura. Precisamente, en contextos de esta naturaleza -como en el ejemplo de ficción propuesto-, sobre todo cuando las reacciones son a posteriori, se puede caer en la tentación de recurrir a excesos y el Estado aplicar métodos desproporcionados, especialmente presionado por una población que exige eficacia a cualquier costo. 


\section{Respuestas Del DeRECho PENAL FRente Al TERRORISMO}

\section{Las distintas posiciones de la doctrina.}

Lo primero que debe decirse es que no se trata de un tema novedoso. Delitos de similar naturaleza han estado "desde siempre" presentes en el Derecho penal -basta tener presente los delitos contra la seguridad interior del Estado que dispone el Código penal chileno-. Pero los peligros del siglo XIX no son los mismos de nuestros tiempos. La diferencia, como se ha subrayado, es la magnitud de las consecuencias, que no pueden desconocerse si se pretende ofrecer respuestas eficientes.

Cómo enfrentar ciertos actos contrarios a la seguridad, sea que las respuestas provengan del Derecho, sea de la fuerza política, fueron también tratados, entre otros, por Kant en su libro Sobre la pazperpetua. Allí señalaba que la paz entre hombres que viven juntos no es un estado de naturaleza (status naturalis); el estado de naturaleza es más bien la guerra, es decir, un estado donde, aunque las hostilidades no hayan sido rotas, existe la constante amenaza de romperlas. Por tanto, la paz es algo que debe ser "instaurada"; pues abstenerse de romper las hostilidades no basta para asegurar la paz, y si los que viven juntos no se han dado mutuas seguridades -cosa que sólo en el estado "civil" puede acontecer- , cabrá que cada uno de ellos, habiendo previamente requerido al otro, lo considere y trate, si se niega, como a un enemigo ${ }^{3}$.

Como nota a la sección segunda Kant agrega: "Pero un hombre (o un pueblo) en estado de naturaleza me priva de esta seguridad y me está lesionando ya, al estar junto a mí en ese estado, no de hecho (facto) ciertamente, pero sí por la carencia de leyes de su estado (statu iniusto), que es una constante amenaza para mí. Yo puedo obligarle a entrar en un estado social-legal o apartarse de mi lado"4.

Hobbes por su parte, afirmaba que cualquiera que atenta contra la seguridad o la supervivencia del Estado no es un delincuente sino un enemigo y contra él no valen la reglas del Derecho sino los de la fuerza. Y la rebelión, no sería más que una renovación del estado de guerras

${ }^{3}$ Kant, Emmanuel, Sobre la paz perpetua ( $7^{\circ}$ ed., traducción de Abellán, Joaquín, Madrid, Tecnos, 2005), p. 14.

${ }^{4}$ Kant, Emmanuel, cit. (n. 3), p. 14.

${ }^{5}$ Hobbes, Thomas, Leviatán (traducción de Escahotado, Antonio, Madrid, ed. Nacional, 1979), p. 386 (cap. $28^{\circ}$ ). Al respecto, Gracia Martín, Luis, El horizonte del finalismo y el "Derecho penal del enemigo" (Valencia, Tirant lo Blanch, 2005), pp. 128 ss. Ahora bien, es cierto como señala Muñoz Conde, Francisco, De nuevo sobre el "Derecho penal del enemigo"(Buenos Aires, Hammurabi, 2005), p. 30, que son autores 
Puede decirse que existen dos grandes posiciones para enfrentar actos de esta naturaleza:

a) Están aquellos que sostienen que el Derecho penal debe mantener las reglas tradicionales -esencialmente conforme a los principios clásicos asentados desde la Ilustración- en el entendido que la mayor eficacia se logra respetando las garantías sin limitación alguna. Y es que toda alteración enturbiaría lo que se espera de la intervención penal. A través de un ejemplo - planteado por Zaffaroni- se puede clarificar lo aseverado: ¿Resulta importante si quien coloca una bomba en un avión en vuelo lo hace para imponer sus ideas políticas, sólo aterrorizar, para cobrar un seguro o eliminar a la empresa competidora? Para ello, se señala, es suficiente que se apliquen las reglas del homicidio, agravantes y concursos. En fin, no tiene sentido buscar tipos especiales y reglas particulares de carácter procesal, pues sólo generan confusión ${ }^{6}$.

b) Otros en cambio, son del parecer de que sí es necesario estructurar un Derecho penal con reglas de imputación y procesales menos estrictas cuando se está frente a fenómenos particularmente graves. En este sentido, se habla de Derecho penal del enemigo ${ }^{7}$, Derecho penal de tercera velocidad o un

del s. XVII y XVIII pero ello no impide desconocer su autoridad y la relevancia de sus afirmaciones.

${ }^{6}$ Zaffaroni, Eugenio, El enemigo en el Derecho penal (Madrid, Dykinson, 2006), p. 183. Ideas semejantes plantea respecto al tratamiento de la criminalidad organizada, pues los instrumentos a los cuales recurre el Derecho penal y procesal penal lo que hacen es establecer un Derecho penal autoritario. Véase: Zaffaroni, Eugenio, Il crimine organizzato: una categoria fallita, en Moccia, Sergio (editor), Criminalità organizzata e risposte ordinamentali (Napoli, Edizioni Scientifiche Italiane, 1999), pp. 63 ss.; Albrecht, Peter-Alexis, Krieg gegen den Terror". Konsequenzen für ein rechtstaaliches Strafrecht en Zeitschrift für die gesamte Strafrechtswissenschaft (2005), p. 857, propone que los delitos de terrorismo sean tratados como delitos de homicidio. Asumiendo que la normativa antiterrorista conforma una legislación de emergencia, fuertemente antigarantista, Villegas, Myrna, Los delitos de terrorismo en el Anteproyecto de Código Penal en Politica Criminal, 2, A3 (2006), pp. 1 ss. (www.politicacriminal.cl consultado el 12 de mayo de 2010).

${ }^{7}$ Sobre la noción introducida por Jakobs hay suficiente literatura, véase, entre otros: JаковS, Günther, Criminalización en el estadio previo a la lesión de un bien jurídico, en Jaковs, Günther, Estudios de Derecho penal (traducción de Peñaranda, Enrique, Madrid, Civitas, 1997), pp. 293 ss. comienza a tratar el tema, en donde traza la distinción con el ciudadano. En p. 98 señala que mientras el Derecho penal del ciudadano optimiza las esferas de libertad, el Derecho penal del enemigo optimiza la protección de bienes jurídicos. Esencialmente, cuando se habla de Derecho penal del enemigo ("Feindstrafrecht"), se caracteriza por adelantar la intervención penal, disminuyendo la proporcionalidad entre el hecho y la pena. Asimismo, se reducen las garantías procesales, por cuanto el autor no garantiza la mínima seguridad cognitiva sobre su comportamiento, al haber abandonado definitivamente el Derecho; JАковs, Günther, La autocompren- 
Derecho penal de la seguridad. En este sentido, Silva Sánchez afirma que si bien un Derecho penal de la tercera velocidad es un mal, éste, bajo ciertas circunstancias, puede ser un mal menor. Es por ello que debe constantemente revisarse a fin de evitar que no responda a consideraciones de eficacia y nece$\operatorname{sidad}^{8}$. En la misma línea, Viganò señala que a través de un enfoque flexible se busca un punto de equilibrio sostenible entre garantías y exigencias de defensa social. Es más, para este autor es inevitable reconocer una doble vía entre la criminalidad común y la criminalidad más peligrosa - como es la terrorista-, disponiendo de una modelación diversificada de garantías?

Sin perjuicio de estas dos grandes posiciones, puede destacarse a quienes han sostenido que el Derecho nada puede hacer en estos casos. Si bien, no es una postura que hoy se defienda, sí puede mencionarse por la envergadura intelectual de quienes la sostuvieron.

Francesco Carrara, en su monumental obra Programa de Derecho criminal, señalaba que no se iba a ocupar de estos delitos de carácter político, pues no podían comprenderse en $s u$ Derecho penal, basado en los principios iluministas. Y es que en sus palabras: en el campo de los delitos contra la seguridad del Estado no existe el Derecho penal. No hay en ellos ni delito ni pena sino una guerra y una defensa directa. La razón jurídica es reemplazada por el derecho de la guerra. Según Carrara, en esta esfera el Derecho penal ya nada podría hacer ${ }^{10}$.

sión de la Ciencia del Derecho penal ante los desafios del presente, en ESER, Albin - HasSEMER, Winfried - BURKHARDT, Björn (coordinadores de la versión alemana); MUÑoz Conde, Francisco (coordinador versión española), La ciencia del Derecho penal ante el nuevo milenio (traducción de Manso, Teresa Valencia, Tirant lo Blanch, 2004), pp. 58 ss.; Jakobs, Günther - Cancio Meliá, Manuel, Derecho penal del enemigo (Madrid, Civitas, 2003),passim.; Cancio Meliá, Manuel - Gómez-Jara Díez, Carlos (coordinador), Derecho penal del enemigo. El discurso penal de la exclusión (Buenos Aires-Montevideo, Edisofer, B de F, 2006); Gracia Martín, Luis, cit. (n. 5), pp. 89 ss., 117 ss., quien hace ver que no se trata de un concepto nuevo. Por el contrario, ya se puede encontrar en la sofística griega; Aponte, Alejandro D., Derecho penal de enemigo vs Derecho penal del ciudadano. El Derecho Penal de emergencia en Colombia: entre la paz y la guerra, en Revista de Derecho de la Universidad Católica del Norte. Sede Coquimbo, 8 (2001), pp. 251 ss.

${ }^{8}$ Silva Sánchez, Jesús María, La expansión del Derecho penal. Aspectos de política criminal en las sociedades postindustriales (2a edición, Madrid, Civitas, 2001), p. 166.

${ }^{9}$ VIGANÒ, Francesco, La luch a contra el terrorismo de matriz islámica a través del Derecho penal: la experiencia italiana (traducción de Londoño, Fernando, en Politica Criminal, 3, A3 (2007), pp. 9-10. (www.politicacriminal.cl consultado el 13 de mayo de 2010).

${ }^{10}$ Para Carrara, Francesco, Programa de Derecho criminal. Parte General (traducción de Ortega Torres, José y Guerrero, Jorge, Bogotá, Temis, 1985) IX, $\$ 3939$, pp. 525-526, a los enemigos hay que tratarlos con la fuerza del poder político, con toda 
Incluso Jiménez de Asúa, al referirse a los criminales de guerra nazis, sostenía que el Derecho penal era un instrumento inútil. Es más, citaba como ejemplo a seguir el de Rusia, que separaba la acción jurídico penal, a través de su Código penal, de la defensa de la revolución y el exterminio (sic) de los contrarrevolucionarios -enemigos-. Por tanto, se trataba de una tarea ejecutiva y no jurídica, que debía ser asumida por la Checa - policía política del régimen- ${ }^{11}$. Por cierto, no deja de llamar la atención las palabras pronunciadas por uno de los más connotados juristas españoles.

De lo expuesto, la cuestión a examinar es la siguiente: el Derecho penal es inútil para enfrentar estos fenómenos y, por tanto no creemos en él. $\mathrm{O}$, por el contrario, sí podemos recurrir al Derecho penal, pero consideraciones de mayor eficiencia llaman a establecer ciertas reglas que pueden significar una flexibilización garantística. Por último, que no deben alterarse las reglas del Derecho penal de corte liberal, pues se corre el riesgo de desnaturalizarlo y de convertirlo en un Derecho penal autoritario.

Por de pronto, no es plausible lo expuesto por Carrara o Jiménez de Asúa y debe desecharse cualquier intento en este orden. Un poder político sin mayor control terminaría por deslegitimarse, dado los excesos y arbitrariedades que en contextos de esta naturaleza tienen lugar, generando así un clima de mayor inseguridad. Por lo demás, el desarrollo del Derecho penal internacional y todas las normas que en este sentido se han dictado, tales como las Convenciones de Ginebra, el Estatuto de Roma para instaurar una Corte Penal Internacional - sólo por citar unas pocas- han puesto en evidencia que el Derecho sí tiene mucho que decir ${ }^{12}$. Basta pensar que la decisión de

la carga de arbitrariedad que ello pudiera significar; ETCHeberry, Alfredo, Derecho penal ( $3^{a}$ edición, Santiago, Editorial Jurídica de Chile, 1998), IV, pp. 97-98, estima razonable la postura de Carrara, pues según su parecer no hay un bien jurídico que proteger. Por tanto, lo único que justifica la incriminación de estos delitos es la defensa social, el pretender vivir pacíficamente.

${ }^{11}$ JIMÉNEZ DE AsÚA, Luis, Un comentario a la anunciada acción penal internacional, en Revista de Ciencias Penales, 10-12 (1944), pp. 335-336.

${ }^{12}$ Sobre el papel que puede cumplir la Corte Penal Internacional frente al terrorismo, ARnold, Roberta, The ICC as a New Instrument for Repressing Terrorism (Ardsley, New York, Transnational Publishers, 2004), passim. Asimismo, la experiencia europea en su lucha contra el terrorismo interno y externo ha puesto de manifiesto que el sistema punitivo sí es un instrumento válido. Así puede apreciarse con la Convención del Consejo de Europa para la prevención del terrorismo http: - - conventions.coe. int - Treaty - EN - Treaties - Html - 196.htm (consultado el 16 de mayo de 2010). $\mathrm{Al}$ respecto, Sotriaux, Stefan, Terrorism and the Limitation of Rights. The ECHR and US Constitution (Oxford and Portland, Oregon, Hart Publishing, 2008), passim, quien analiza no sólo el panorama legislativo europeo y norteamericano, sino también examina la jurisprudencia de la Corte Europea de Derechos Humanos y de la Suprema Corte de los Estados Unidos; BAUccio, Luca, L'accertamento del fatto reato di terro- 
establecer los Tribunales penales internacionales para la ex Yugoslavia y Ruanda se adoptó por las Naciones Unidas -conforme al capítulo VII de la Carta de la ONU- . Fue la propia comunidad internacional la que exigió reestablecer el imperio del Derecho, pues era el camino más legítimo para alcanzar la paz ${ }^{13}$. El tiempo ha demostrado que fue una decisión acertada.

Pues bien, si no debe aceptarse, bajo ninguna circunstancia, la idea de la fuerza política como herramienta predominante para enfrentar el terrorismo, significa que el iter a seguir es la jurisdiccionalización del problema en cuestión, en todas sus manifestaciones, incluso las más intensas ${ }^{14}$. Llegado a este punto, surge una segunda cuestión y es la de resolver cómo brindar seguridad a la ciudadanía a través del Derecho penal, sin que ello suponga poner en

rismo internazionale. Aspetti teorici e pratici (Milano, Giuffrè, 2005), passim; PICCHIO Forlati, Maria Laura (editora), Controllo degli armamenti e lotta al terrorismo tra Nazione Unite, Nato e Unione Europea (Padova, Cedam, 2007), passim.

${ }^{13}$ Las palabras de Atoki Ilesa, embajador y representante de la República Democrática del Congo ante la Naciones Unidas permiten comprender el espíritu que inspira la Corte Penal Internacional, y por tanto la importancia del camino del Derecho: "Mientras les estoy hablando se están cometiendo graves crímenes en Kisangani, Congo Oriental. Los que están cometiendo estos crímenes no han comparecido ante la justicia y hasta se han burlado de las resoluciones del Consejo de Seguridad que llaman a terminar el conflicto de manera pacífica. Esto evidencia que la impunidad es uno de los factores esenciales que impiden que haya paz y seguridad internacional en nuestra región. Desde nuestra perspectiva, la Corte Penal Internacional constituye un importante avance en la lucha contra la impunidad, una mano extendida hacia las víctimas que habían perdido toda esperanza, una enérgica advertencia a los asesinos, incluyendo a aquellos de la región de los Grandes Lagos donde la cultura de la impunidad y los conflictos sangrientos han producido las más terribles violaciones a los derechos humanos y verdaderos desastres humanitarios. La Corte Penal Internacional no sólo servirá para enjuiciar a los responsables de los crímenes de su competencia, sino que además servirá para disuadir a los que cometen tales crímenes. A sabiendas de esto, se puede entender mejor el compromiso del Congo con la creación de una corte permanente cuyo fin es que los crímenes que han remecido la conciencia de la humanidad no queden sin castigo". http: - - coalitionfortheicc.org - documents - monitor21.200106.espanol.pdf (consultado el 25 de mayo de 2010).

${ }^{14}$ En estos mismo términos, Viganò, Francesco, cit. (n. 9), p. 7; riesgos de una desjurisdiccionalización se pueden apreciar en la legislación norteamericana, claramente a partir del 11 de septiembre de 2001, véanse: Susan, Herman - Finkelman, Paul (editores), Terrorism, Goverment, and Law. National Authority and Local Autonomy in the War on Terror (Westport, Connecticut, Praeger Security International, 2008), passim; Sottiaux, Stefan, cit. (n. 12), pp. 35 ss.; Vervaele, John, La legislazione anti-terrorismo negli Stati Uniti. Inter arma silent leges? en Rivista Italiana di Diritto e Procedura Penale (2005), pp. 739 ss. Sobre la legislación y práctica antiterrorista de cinco países angloparlantes: Australia, Nueva Zelanda, Canadá, Reino Unido y Estados Unidos: Douglas, Roger, Proscribing Terrorist Organizations: Legislation and Practice in five English-Speaking en Criminal Law Journal, 32 (2008), pp. 90 ss. 
entredicho el basamento axiológico sobre el cual se asienta el Derecho penal. Como acertadamente afirma Silva Sánchez, una legislación penal se legitima en la medida que es capaz de sintetizar dos pretensiones sociales básicas: la protección de sus intereses y la libertad -prevención y garantías- . Es decir, lo propio de una democracia representativa es velar porque dicho equilibrio se respete: ciudadanos que eventualmente pueden ser víctimas tendrán un interés en obtener una mayor protección, pero también esos mismos ciudadanos exigirán mayores garantías si se les imputa un delito ${ }^{15}$.

\section{Una necesaria flexibilización del marco garantístico.}

La cuestión a debatir es la siguiente: es plausible el tradicional discurso de que cualquier modificación del edificio garantístico sobre el cual se asienta el Derecho penal constituye un riesgo. Me parece que no. Por de pronto, me parece aún más peligroso el ejemplo expuesto más arriba. ¿Es posible considerar seriamente que el fin es irrelevante? Que es lo mismo poner una bomba en un avión para aterrorizar que para cobrar un seguro. Por supuesto que no tienen el mismo significado.

Como muy bien señala Viganò: "Precisamente a efectos de no disipar el patrimonio esencial de las garantías y principios que conforman nuestra propia identidad occidental, hoy más que nunca es necesaria una seria toma de conciencia de la extrema peligrosidad y del carácter anómalo del fenómeno criminoso representado por el terrorismo de matriz islámica ${ }^{16}$. La disponibilidad para el martirio vuelve a muchos terroristas - o aspirantes a tales -bastante menos motivables por la norma penal que la generalidad de los criminales, a la vez que exalta su carga de peligrosidad: porque en este modo cualquiera está en condiciones de transformar su propio cuerpo en un arma letal. Pero si lo anterior es así, entonces quizás aparecerá como inevitable que la función de neutralización de la peligrosidad individual, propia del derecho penal en su complejo, resalte en primer plano frente a la 'clásica' función 'disuasiva' de la norma penal, o bien respecto a su función de 'integración social'. Más adelante afirma: 'Todo lo cual significa reconocer abiertamente la inevitabilidad de una doble vía para la criminalidad común

${ }^{15}$ Silva Sánchez, Jesús María, Los principios inspiradores de las propuestas de un Derecho penal europeo. Una aproximación critica en Revista Penal, 13 (2004), p. 142; Silva Sánchez, Jesús María, Aproximación al Derecho penal contemporáneo (Barcelona, Bosch, 1992), pp. 186 ss.; BERGALLI, Roberto, Libertad y seguridad: un equilibrio extraviado en la modernidad tardia en Losano, Mario - Muñoz Conde, Francisco, El Derecho ante la globalización y el terrorismo (Valencia, Tirant lo Blanch, 2004), pp. 59 ss.

${ }^{16}$ Aclaro que mis argumentaciones no se dirigen a una forma de terrorismo en particular. 
y para ciertas formas de criminalidad particularmente peligrosas (in primis el terrorismo). También el enfrentamiento de estas últimas realidades deberá permanecer confiada al derecho y a la jurisdicción penal, pero con una modelación diversificada de la garantías fundamentales reconocidas a los imputados y condenados" 17 .

No comparto el discurso "alarmista”, esto es, que plantear una limitación a las garantías constituye un riesgo que debe prevenirse a toda costa; que el Derecho penal liberal propio de un Estado de Derecho no puede cometer la ingenuidad de cederle un espacio y menos aún su instrumento orientador, determinado por los principios iluministas, a un Derecho penal autoritario -entendiendo como tal un derecho penal que enfatice en la seguridad o una mayor optimización en la protección de bienes jurídicos- ${ }^{18}$.

En primer lugar, siempre se ha entendido -incluso por pensadores de la Ilustración- que existen ciertos comportamientos que requieren de un tratamiento más riguroso. El propio Beccaria individualizaba a los delitos de lesa majestad como aquellos que destruyen a la sociedad y quienes la representa, siendo por tanto los más dañosos. Es más, siendo en general contrario a la pena de muerte, sostenía que en algunos casos podía estimarse necesaria cuando los intereses de la seguridad de la nación así lo reclamaban ${ }^{19}$. Por tanto, no parece cierto que se estaría traicionando el ideario iluminista.

Por lo demás y como se ha dicho hasta el cansancio, el "viejo y buen Derecho penal liberal" que se cimenta sobre estrictas garantías frente al poder punitivo del Estado nunca ha existido ${ }^{20}$. Incluso los procesos codificadores que tuvieron lugar durante el siglo XIX, y que recogieron los principios de ascendencia iluminista, también dispusieron de sendos títulos referidos a los

${ }^{17}$ Viganò, Francesco, cit. (n. 9), p. 9. En este mismo sentido, Silva SáncheZ, Jesús María, cit. (n. 8), p. 165: "A la vez, en casos de esta naturaleza (criminalidad de Estado, terrorismo, criminalidad organizada) surgen dificultades adicionales de persecución y prueba. De ahí que, en estos ámbitos, en los que la conducta delictiva no sólo desestabiliza una norma en concreto, sino todo el Derecho como tal, pueda plantearse la cuestión del incremento de penas de prisión, a la vez que la de la relativización de las garantias sustantivas y procesales". (La cursiva es mía). Acerca de las particulares que presentan los integrantes de grupos terroristas islámicos, CANo PAÑos, Miguel Ángel, Perfiles de autor del terrorismo islamista en Europa en Revista Electrónica de Ciencia Penal y Criminología, 11-07 (2009), pp. 1 ss. (http: - - criminet.ugr.es - recpc - consultado el 17 de mayo de 2010).

${ }^{18} \mathrm{Al}$ respecto, Zaffaroni, Eugenio, cit. (n. 6), p. 184.

${ }^{19}$ Con ello se pone en evidencia que también Beccaria admitía que ciertas formas de criminalidad peligrosa - como es hoy el terrorismo- podían sujetarse a otras reglas. Beccaria, Cesare, Dei delitti e delle pene (edición a cargo de Franco Ventura, Torino, Giulio Einaudi, 1981), pp. 24 y 62.

${ }^{20}$ Silva SÁnchez, Jesús María, cit. (n. 8), p. 149 ss. 
delitos contra la seguridad del Estado, con reglas especiales y más rigurosas que respecto de los delitos "tradicionales".

Por otro lado, tampoco es admisible que se plantee que un Derecho penal de doble criminalidad se opone al Estado de Derecho. Precisamente, cuando autores como Jakobs, Silva Sánchez o Viganò argumentan en este orden lo hacen pensando en un Derecho penal propio de un régimen democrático, recurriendo a todas sus instituciones. Sostener lo contrario, es caer en discursos ideológicos inconducentes ${ }^{21}$. Por último, no me parece razonable sostener que bastan las reglas "clásicas" aplicables a cualquier delito para enfrentar fenómenos como el terrorismo cuando a todas luces el mundo camina por otro derrotero -los desafíos del siglo XXI son otros, muy diversos a los del siglo XIX-. Nos guste o no el mundo cambió tras el 11 de septiembre de 2001 y el teórico debe ofrecer un discurso razonable en este sentido, precisamente para evitar desviaciones y arbitrariedades en que puede caer la autoridad. No hacerlo alejaría aún más a la ciencia penal, que seguiría sin influir en quienes realmente "discuten", bien o mal, el Derecho penal, como son los legisladores. Asimismo, es importante que ofrezca también un discurso a la opinión pública, que no sea sólo comprensible para unos pocos iniciados ${ }^{22}$.

${ }^{21}$ Ferjoó Sánchez, Bernardo, El Derecho penal del enemigo y el Estado democrático de Derecho, en Revista de Derecho Penal Contemporáneo, 16 (2006), p. 135: "Una vez aireadas ciertas cuestiones ya no es posible esconder la cabeza bajo tierra como los avestruces, o mirar para otro lado. Se trata de retos a los que antes o después la ciencia del derecho del siglo XXI tiene que hacer frente. Tenemos, por tanto, que analizar qué puede aportar al final -a pesar del rechazo- la idea del derecho penal del enemigo. Por otro lado, si dogmáticamente podemos definir las características de lo que podemos denominar derecho penal del enemigo e identificarlo, ello nos puede servir para deslegitimar apartados concretos del ordenamiento vigente; es decir, se trata de un instrumento más para deslindar los modelos legítimos de los modelos ilegítimos de derecho penal -no más difuso que las referencias al derecho penal simbólico o al derecho penal del riesgo-". Véase: CARnevali, Raúl, Derecho penal como ultima ratio. Hacia una politica criminal racional, en CARNEVALI, Raúl, Problemas de política criminal y otros estudios (Santiago, LegalPublishing, 2009), pp. 25 ss.; MARINUCCI, Giorgio - Dolcini, Emilio, Derecho penal 'minimo' y nuevas formas de criminalidad, traducción de Carnevali, Raúl, en Revista de Derecho de la Universidad Católica del Norte. Sede Coquimbo, 8 (2001), pp. 231 ss.

${ }^{22}$ Schünemann, Bernd Consideraciones criticas sobre la situación espiritual de la ciencia jurídico-penal alemana (Bogotá, Universidad Externado de Colombia, 1996), p. 54, afirma que en Alemania la ciencia penal muchas veces se enfrasca en discusiones sin mayor relevancia, perdiendo así la oportunidad de influir en la praxis; MUÑoz Conde, Francisco, Presente y futuro de la Dogmática jurídico-penal, en Revista Penal, 5 (2000), p. 45, destaca que la dogmática muchas veces se aleja de la praxis y se orienta al interior del sistema; Quintero Olivares, Gonzalo, Adonde va el Derecho penal. Reflexiones sobre las Leyes Penales y los penalistas españoles (Madrid, Civitas, 2004), pp. 91 ss. resalta el desinterés de los gobernantes españoles por conocer las peticiones de la 
Indudablemente que cuando se plantea un determinado marco garantístico para enfrentar actos de particular peligrosidad y potenciales efectos catastróficos, se debe tener en cuenta ciertos criterios valorativos, que permitan trazar un mínimo indisponible. Éste no puede sino construirse sobre la base del respeto a la persona y dignidad humana, reconocida en constituciones políticas y tratados internacionales, como la Convención europea de derecho humanos y la Convención interamericana de derechos humanos ${ }^{23}$. Conforme a lo anterior, no es posible adoptar medidas que supongan una instrumentalización del sujeto, convirtiendo a éste en un mero objeto, cualquiera sea el propósito que se persiga. Es decir, en la ponderación de intereses -dignidad del sujeto y seguridad colectiva- primará siempre el sujeto. Es por lo anterior, que no puede justificarse la tortura, ni todo aquello que pueda suponer someterlo a tratos inhumanos o degradantes ${ }^{24}$. Precisamente, como señala Roxin, la superioridad moral del Estado frente al delincuente reside precisamente en que no utiliza los mismos medios que éste ${ }^{25}$. En todo caso, más abajo se examinará la tortura en ciertos casos excepcionales, y cómo debería responder el Derecho.

Por último, frente a los riesgos de "contaminación" de un Derecho de esta naturaleza al Derecho penal "clásico" -que por cierto puede existir- , estimo que se disponen de los instrumentos suficientes para evitarlo. En efecto, al Tribunal Constitucional le corresponde ejercer el debido control de racionalidad legislativa, de manera que las normas penales que en este orden se puedan establecer respondan al entramado de garantías dispuestas en la Constitución y tratados internacionales ${ }^{26}$. Por tanto, pueda declararse

doctrina; Carnevali, Raúl, cit. (n. 21), p. 21; Viganò, Francesco, cit. (n. 9), p. 9.

${ }^{23}$ Silva Sánchez, Jesús María, Retos cientificos y retos politicos de la ciencia del Derecho penal, en Revista de Derecho penal y Criminología, 9 (2002), p. 86; VIGanò, Francesco, cit. (n. 9), p. 10.

${ }^{24}$ Carella, Gabriella, Nominalismo e lotta al terrorismo internazionale: il caso delle extraordinary renditions, en Venturini, Gabriella - BARIATti, Stefania (editores Diritti individuali e giustizia internazionale. Liber Fausto Pocar (Milano, Giuffrè, 2009), p. 122, señala que se trataría de un artificio retórico pretender colocar en un mismo plano seguridad y derechos humanos, pues los derechos son medidas de protección y la seguridad, medida de prevención. Esto último supone obligaciones de medios y no de resultados. En consecuencia, para esta autora, jamás pueden ponerse en el mismo nivel: no son equiparables protección y prevención. Por un lado, está la segura violación de un derecho y por la otra, la incierta ventaja en términos de seguridad.

${ }^{25}$ Roxin, Claus, ¿Puede admitirse o al menos quedar impune la tortura estatal en casos excepcionales? (traducción de Gómez Navajas, Justa), en Cuadernos de Politica Criminal, 83 (2004), p. 29.

${ }^{26} \mathrm{Hinsch}$, Hans Joachim, Problemas actuales de la legislación penal propia de un Estado de Derecho (traducción de Guzmán, José Luis), en De Figueredo Dias, Jorge - Serrano Gómez, Alfonso - Politoff Lifschitz, Sergio y otros (directores), El 
en su caso la inconstitucionalidad de estas disposiciones. A través de un exhaustivo trabajo en esta dirección permitirá fijar el marco sobre el cual ha de actuar el legislador. A lo anterior, debe también tenerse en consideración la importante labor de "precisión de la norma" que les corresponde a los jueces. Y es que una jurisprudencia motivada y profunda también puede brindar la necesaria seguridad jurídica para el ciudadano ${ }^{27}$.

\section{Algunas consideraciones respecto del terrorismo que justifican un modelo} diverso. Análisis de la normativa italiana.

Que la respuesta debe provenir del Derecho penal, incluso tomando en cuenta las particularidades del fenómeno que debe enfrentar, ya pone de manifiesto una decisión de especial importancia, y es que la sociedad no renuncia a su identidad cultural. En efecto, se reconoce como base fundamental el respeto a la dignidad humana, con todo su entramado de derechos y libertades fundamentales, y que se recoge en la estructura del sistema penal. Es decir, bajo ninguna circunstancia puede tolerarse recurrir a medidas eficientistas a cualquier costo que terminarían por deslegitimar cualquier intervención en este orden ${ }^{28}$.

Ahora bien, que se tome una postura a favor de enfrentar el terrorismo con los instrumentos que brinda el Derecho penal, esto es, estimando que la jurisdiccionalización del problema puede ser una herramienta eficiente, no impide a su vez considerar que para ello deben adoptarse ciertas medidas que pueda significar un modelo garantístico particular. Como se ha indicado supra, es preciso estructurar un sistema que sea lo suficientemente equilibrado, que refleje un debido balance entre, por una parte, los derechos del imputado, y por otro, lo que representa la seguridad de la sociedad.

$\mathrm{Al}$ respecto, debe tenerse presente que el fenómeno terrorista contiene ciertas características que no se pueden desatender y que, precisamente, avalan una postura en la dirección indicada. Por de pronto, considerando las graves consecuencias que pueden derivarse de actos terroristas, adquiere particular relevancia el recurso de instrumentos dirigidos a la minimización de riesgos. Por tal motivo, la orientación del ordenamiento debe tener un carácter prospectivo más que de orden retrospectivo, como sí acontece en el Derecho penal "clásico". El punto de especial atención es el hecho que va a

penalista liberal. Homenaje a Manuel de Rivacoba y Rivacoba (Buenos Aires, Hammurabi, 2004), pp. 133-134.

${ }^{27}$ Sobre el llamado al juez de "precisar" la norma, Hassemer, Winfried, Fundamentos del Derecho penal (traducción de Muñoz Conde, Francisco - Arroyo Zapatero, Luis, Barcelona, Bosch, 1984), p. 314-319.

${ }^{28}$ Carnevali, Raúl, cit. (n. 21), pp. 29 ss.; Silva Sánchez, Jesús María, Eficiencia y Derecho penal, en Anuario de Derecho penal y Ciencias Penales (1996), p. 127. 
cometerse más que el hecho cometido. Ello quiere decir que el ordenamiento jurídico debe también adoptar medidas que presten el debido cuidado a los actos que están por realizarse ${ }^{29}$.

Por lo anterior, resulta plenamente justificable disponer de normas que supongan la punición de determinados actos preparatorios. Parece evidente que conductas como las terroristas -así como también otras propias de la criminalidad organizada - requieren de herramientas eficaces: una intervención penal oportuna, sin tener que esperar estar frente a actos de ejecución. Sostener lo contrario, podría tornar inútil cualquier medida preventiva. Indudablemente, una decisión político criminal de esta naturaleza, tan incisiva en el ejercicio de las libertades fundamentales, requiere de una rigurosa selección de conductas que satisfagan principios como los de lesividad o proporcionalidad.

Lo expuesto podría inscribirse dentro de la llamada "teoría de la anticipación”. En efecto, tratándose de delitos de organización como es el terrorismo, supone que se está frente a dimensiones institucionales que favorecen la comisión de delitos dentro de su contexto. En consecuencia, las sanciones de que se disponen para actos vinculados a la organización se justificarían sobre la base de anticipar la protección de bienes jurídicos que se verían afectados por la comisión de los delitos fines de la organización ${ }^{30}$. Es decir, dado el incremento de peligrosidad que representa la organización, es que se justificaría adelantar la intervención punitiva ${ }^{31}$.

Precisamente, la regulación italiana dispone de una serie de disposiciones en la dirección descrita, esto es, de sancionar excepcionalmente ciertos actos preparatorios. Como es sabido por todos, Italia ha conocido de cerca el terrorismo interno - las Brigadas Rojas en la década de los setenta y ochenta- , así como los actos de la mafia, que si bien no puede calificarse en rigor de actividad terrorista, sí comparte ciertas particularidades propias de la criminalidad organizada que hacen necesario disponer de normas particulares para su tratamiento ${ }^{32}$. Por otro lado, y sobre todo a partir de

${ }^{29}$ Cancio Meliá, Manuel, Derecho penal del enemigo y delitos de terrorismo, en Revista de Derecho Penal Contemporáneo, 3 (2003), p. 37.

${ }^{30}$ Así lo expone, Silva Sánchez, Jesús María, La “intervención a través de organización" ¿una forma moderna de participación en el delito? en Dolcini, Emilio - PALIERo, Carlo Enrico (editores), Studi in onore di Giorgio Marinucci (Milano, Giuffrè, 2006), II, p. 1880.

${ }^{31}$ En estos términos se expresa, Cancio Meliá, Manuel, Sentido y límites de los delitos de terrorismo, en Serrano-Piedecasas, José Ramón - Demetrio Crespo, Eduardo (directores), Terrorismo y Estado de Derecho (Madrid, Iustel, 2010), pp. 389390.

${ }^{32}$ La literatura italiana sobre la mafia y la criminalidad organizada es abundante. Un elenco bastante exhaustivo sobre el delito de asociación de tipo mafioso del artí- 
los acontecimientos del 11 de septiembre, de marzo de 2004 en Madrid y de julio de 2005 -atentado en Londres- , así como la presencia de bases de reclutamiento de terroristas islámicos en suelo italiano, han motivado modificaciones de su ordenamiento penal.

Por de pronto y con acierto, el Código Penal italiano ha dejado atrás la clásica concepción del terrorismo, propio de los años setenta y ochenta, vinculada más bien con la subversión del orden constitucional interno ${ }^{33}$. En efecto, si bien contiene normas en este sentido - artículo 270 y 270 bis - hoy va más allá, pues se entiende que pueden también realizarse actos terroristas que no tengan propiamente un propósito subversivo ${ }^{34}$. Por ejemplo, poner una bomba en la embajada israelí de Roma -o el mismo atentado de Madrid en marzo de 2004- , no procuran revertir el orden institucional, ni socavar el régimen político democrático, sólo pretenden intimidar y dar a conocer el poder destructivo de una organización que les permita imponer sus términos. Es más, como se verá, también se sancionan conductas que no se dirijan a generar el terror en la población italiana, pero que al desarrollarse en su territorio sí pueden afectar a otro Estado o a una organización internacional. Por ejemplo, el reclutamiento o adiestramiento de células terroristas en Italia para que actúen en los Estados Unidos.

culo 416 bis del Código Penal italiano en Dolcini, Emilio - Marinucci, Giorgio (editores), Codice Penale commentato (2a edición, Milano, Ipsoa, 2006), II, p. 3.144 ss. Asimismo, sobre las particularidades de la criminalidad organizada, véanse, entre otros: Parano, Carola - Centonze, Alessandro (editores), L'attivitá di contrasto alla criminalità organizzata (Milano, Giuffrè, 2005); Patalano, Vincenzo (editor), Nuove strategie per la lotta al crimine organizzato transnazionale (Torino, Giappichelli, 2003); FORNASARI, Gabriele (editor), Le strategie di contrasto alla criminalitá organizzata. Nella prospettiva di diritto comparato (Padova, Cedam, 2002); Militello, Vincenzo - Paoli, Letizia - ARNOLD, Jörg (editores), Il crimine organizzato come fenomeno transnazionale. Forme di manifestazione, prevenzione e repressione in Italia, Germania e Spagna (Freiburg, Ed. Iuscrim, Max Planck Institut, 2000); Moccia, Sergio (editor), Criminalità organizzata e risposte ordinamentali (Napoli, Edizioni Scientifiche Italiane, 1999).

${ }^{33}$ Rosi, Elisabetta, Terrorismo internazionale: le nuove norme interne di prevenzione e repressione. Profili di diritto penale sostanziale, en Diritto Penale e Processo, 1 (2002), p. 155; NARDUCCI, Giuseppe, Nella differenza tra atti terroristici ed eversivi $i$ confini del "nuovo" reato, Diritto e giustizia, 3 (2002), pp. 10 ss.; Reiteano, Simona, Le misure di contrasto al terrorismo internazionale tra Unione Europea e normativa italiana di adattamento, en L'Indice Penale (2004), pp. 1.173 ss.; para Villegas, Myrna, cit. (n. 6), pp. 9-10, el bien jurídico protegido en los delitos terroristas es el ordenamiento constitucional democrático.

${ }^{34} \mathrm{El}$ propio artículo 270 bis distingue entre asociaciones con finalidades terroristas y aquellas dirigidas a la subversión de orden democrático. Véase: Dolcini, Emilio MARINUCCI, Giorgio, cit. (n. 32), I, p. 1949. 
Pues bien, para poder enfrentar con eficacia actos como los descritos es indispensable que el ordenamiento penal disponga de normas que impliquen un adelantamiento de la barrera protectora del Derecho penal, castigando como delitos actos que son preparatorios de aquel propiamente terrorista ${ }^{35}$. En este sentido, el artículo 270 quater penaliza los actos de enrolamiento en estructuras de carácter militar con fines terroristas, lo mismo sucede con las actividades de adiestramiento con fines terroristas, tanto respecto de quien suministra instrucciones como del que las recibe - artículo 270 quinquies36. Tales actos se sancionan aun cuando la acción terrorista propiamente tal tenga lugar en el extranjero, o incluso, aunque ésta no se realice. Disponer de normas de esta naturaleza responde a particularidades que son muy propias de las organizaciones terroristas, como es su carácter transnacional. Por tanto, se requiere de políticas de persecución que comprendan tales supuestos.

Ahora bien, para evitar los riesgos que siempre llevan consigo las normas que anticipan la intervención penal, en cuanto al debido ejercicio de las libertades fundamentales, es que estas conductas deben interpretarse a la luz del artículo 270 sexies del Código penal italiano, que precisa las conductas con finalidad de terrorismo ${ }^{37}$. Por de pronto, destaca en el plano objetivo que los actos deben ser idóneos para causar un grave daño a un país o a una organización internacional. Es decir, debe realizarse un juicio de probabilidad -prognosis-: no es preciso que los actos hayan ya provocado un grave daño, basta que éstos puedan generarlo ${ }^{38}$. De haberse llevado a cabo los actos propuestos, conforme a los antecedentes reunidos, hubiesen provocado graves perjuicios. Por tanto, y a fin de respetar el principio de ofensividad, las con-

${ }^{35}$ Cumpliendo de este modo con las normas provenientes de la Unión Europea: Decisión Marco 2002 - 475 - JAI Véase: http: - - eur-lex.europa.eu - LexUriServ LexUriServ.do?uri=OJ:L:2002:164:0003:0007:ES:PDF (consultado el 23 de mayo de 2010), luego modificada por la Decisión Marco 2008 - 919 - JAI Ver http: - - eurlex.europa.eu - LexUriServ - LexUriServ.do?uri=OJ:L:2008:330:0021:0023:ES:PDF (consultado el 23 de mayo de 2010).

${ }^{36}$ Pistorelli, Luca, Punito anche il solo arruolamento, en Guida al Diritto, 33 (2005), pp. 55 ss.

37 "Artículo 270 sexies: "Conductas con finalidad de terrorismo. 1. Son consideradas con finalidad de terrorismo las conductas que, por su naturaleza o contexto pueden ocasionar graves daños a un pais o a una organización internacional y son ejecutadas con el propósito de intimidar a la población u obligar a los poderes públicos o a una organización internacional a ejecutar o abstenerse de ejecutar cualquier acto o para desestabilizar o destruir las estructuras politicas fundamentales, constitucionales, económicas y sociales de un pais o de una organización internacional. Asimismo, las otras conductas definidas como terroristas o cometidas con finalidad de terrorismo por convenciones u otras normas de derecho internacional que vinculan a Italia".

${ }^{38}$ VAlSECCHI, Alfio, Brevi osservazioni di diritto penale sostanziale, en Diritto Penale e Processo, 10 (2005), p. 1.224. 
ductas desplegadas deben ser objetivamentepeligrosas. Si bien no se indica qué bienes jurídicos pueden verse afectados, a fin de precisar el presupuesto del grave daño, se ha entendido que aquéllos pueden ser de naturaleza personal, patrimonial o colectiva ${ }^{39}$. Lo anterior, se desprende del propio artículo 270 sexies -recogiendo a su vez disposiciones de la Unión Europea- al incluir actos que destruyan estructuras gubernativas de un Estado -ya sea el propio o uno extranjero- o de una organización internacional. Además, diversos tipos penales del Código penal italiano relativos al terrorismo se refieren a conductas que pueden atentar, ya sea a bienes personales (artículo 280), como a bienes patrimoniales y colectivos (artículo 280 bis).

De lo expuesto, ya es posible establecer ciertas conclusiones que nos permitirán precisar cuál es el bien jurídico afectado por los delitos de terrorismo. Prima facie y como ya se ha explicado, éste no puede reducirse al orden constitucional interno de los Estados. Además, hoy el terrorismo ha adquirido un carácter internacional que difícilmente puede conciliarse con una concepción más bien asociada al orden interno. Precisamente, a fin de poder disponer de elementos de juicio que permitan precisar el o los intereses tutelados, la mirada debe dirigirse hacia otra perspectiva. En este sentido, debe tenerse en consideración las finalidades subjetivas perseguidas con el acto terrorista -elemento teleológico-. Pues bien, el artículo 270 sexies ya aludido señala las siguientes alternativas: $i$ ) intimidar a la población; $i i)$ constreñir a los poderes públicos o a una organización internacional a ejecutar o abstenerse de ejecutar una acto cualquiera; o iii) desestabilizar o destruir las estructuras políticas fundamentales, constitucionales, económicas o sociales de un país o de una organización internacional ${ }^{40}$.

El juez debe siempre verificar que los actos desplegados por el o los agentes sean objetivamente idóneos para lograr algunos de los tres propó-

${ }^{39}$ VAlSECCHI, Alfio, cit. (n. 38), p. 1.225.

${ }^{40}$ Considerando lo que indica la última parte del artículo 270 sexies, debe agregarse lo que disponen las normas de Derecho internacional vinculadas a Italia. Pues bien, en este sentido el artículo 2 de la Convenio de las Naciones Unidas contra el financiamiento al terrorismo señala -entre otras conductas- que se está frente a una conducta terrorista cuando: "el propósito de dicho acto, por su naturaleza o contexto, sea intimidar a una población u obligar a un gobierno o a una organización internacional a realizar un acto $o$ a abstenerse de hacerlo", en http: - - www.cinu.org.mx - multi - ter - documentos - Cfinancsp.pdf (consultado el 29 de mayo de 2010). Véase: VALSECCHI, Alfio, Il problema della definizione di terrorismo en Rivista Italiana di Diritto e Procedura Penale (2004), pp. 1.138 ss.; para VIGANò, Francesco, cit. (n. 9), p. 18, la referencia a la intimidación de la población -la más representativa de la actividad terrorista- debe relacionarse con la Declaración Universal de los Derechos Humanos, cuando en su preámbulo declara que una de las aspiraciones más elevadas del hombre es vivir en un mundo libre de temor. 
sitos recién individualizados -modelo mixto subjetivo-objetivo- ${ }^{41}$. Debe acreditarse que al formar parte de estructuras organizativas que disponen de ciertos medios pueden alcanzar lo que se proponen. En consecuencia, no se sanciona por el sólo hecho de pertenecer o integrar una organización, sino porque sus comportamientos individuales conllevan un riesgo jurídico penalmente relevante, a saber, de que pueden llevarse a cabo los delitos fines de la organización ${ }^{42}$.

Especial atención merece la referencia que se hace a la tercera hipótesis: desestabilizar o destruir las estructuras políticas fundamentales, constitucionales, económicas o sociales de un país o de una organización internacional. Se trataría pues, de un supuesto de subversión, pero ya no reducida al territorio italiano como era en el pasado, sino que ampliada a otros Estados ${ }^{43}$. La duda surge respecto de Estados no democráticos, que al vivir bajo dictaduras, ha determinado la organización de grupos con el objeto de enfrentarlas. En principio, la norma italiana no dispone limitaciones, por lo que habría que entender que también se trataría de actos terroristas. Obviamente aquello exige matizaciones, pues se puede caer en el absurdo de calificar como tal cualquier forma de resistencia a gobiernos dictatoriales. Incluso calificar de terroristas a grupos que cuentan con alguna forma de reconocimiento por el Derecho internacional.

Precisamente, una de las grandes dificultades a la que se enfrenta el Derecho en general y no sólo penal, es cómo distinguir cuándo se está frente a grupos que merecen la calificación de terroristas y cuándo no. En efecto, se pueden presentar consideraciones de orden político que empujen a un Estado a estimar como terrorista a un movimiento, en circunstancias que para otros Estados éste no es más que un grupo que lucha contra un Estado opresor. Los grupos insurgentes han existido siempre, basta considerar los movimientos independistas. Asimismo, los llamados movimientos de liberación nacional, a los que se puede reconocer como sujetos de Derecho internacional, también generan fuertes controversias ${ }^{44}$. Por ejemplo, Hamas es reconocido por

${ }^{41}$ Pérez Cepeda, Ana Isabel, Definición del delito de terrorismo como un delito internacional, en Serrano-Piedecasas, José Ramón - Demetrio Crespo, Eduardo (directores), Terrorismo y Estado de Derecho (Madrid, Iustel), 2010), p. 56; Valsecchi, Alfio, cit. (n. 38), p. 1.226.

${ }^{42}$ Silva SÁnchez, Jesús María, cit. (n. 30), p. 1.881; Grosso, Carlo Federico, Le fattispecie associative: problemi dommatici e di politica criminale, en Moccia, Sergio (editor), Criminalità organizzata e risposte ordinamentali (Napoli, Edizioni Scientifiche Italiane, 1999), p. 140.

${ }^{43}$ Viganò, Francesco, cit. (n. 9), p. 16; VAlSECCHI, Alfio, cit. (n. 38), p. 1.225.

${ }^{44}$ Debe tenerse en cuenta que en el Derecho internacional existen normas que reconocerían a tales movimientos o grupos. Así, la propia Carta de las Naciones Unidas consagra el principio de libre determinación de los pueblos o la Convención de Ginebra 
algunes sectores palestinos como un movimiento político y para Israel es un organización terrorista. Hace un tiempo, el presidente venelozano Hugo Chávez planteó reconocer a las FARC la calidad de grupo insurgente, en circunstancia que para el gobierno colombiano son terroristas.

No sólo en materia de Derecho sustantivo, el Derecho italiano ha desarrollado herramientas para enfrentar una criminalidad de esta naturaleza. Es así que en sede procesal y penitenciaria se han dispuesto las llamadas medidas premiales, esto es, toda una serie de instrumentos que se aplican a quienes colaboran de manera relevante con la justicia - "pentiti"-45. Estos han mostrado ser eficaces en la lucha contra las asociaciones mafiosas, tomando en cuenta el especial papel que aquí le cabe al "omertà", que es una particular forma de silencio: una especie de reglas de solidaridad entre sus miembros, que torna impermeable a la asociación - para sus integrantes son más importantes las normas de la asociación que las del Estado- ${ }^{46}$. Asimismo, estas medidas cumplieron una relevante función en el desmantelamiento de uno de los grupos terroristas más violentos que asolaron Italia durantes los setenta y ochenta, como fueron las Brigadas Rojas. Pues bien, entre las medidas se disponen: la protección a los colaboradores, la rebaja de penas, como así también excepciones a los colaboradores para que puedan disfrutar de medidas alternativas a la pena (artículo 4 bis, 58 ter del ordenamiento penitenciario).

Es cierto que medidas de esta naturaleza pueden generar riesgos desde la perspectiva de la información que se entrega, pues con el propósito de obtener beneficios ésta puede ser tergiversada. Pero ello es un riesgo inherente a toda colaboración con la justicia, la que debe ser contrastada con otros antecedentes que obren en poder del Ministerio Público o del juez, en su caso. El sistema procesal cuenta con herramientas que le permiten confrontar los dichos del colaborador. Tampoco me parece razonable plantear su rechazo desde una perspectiva ética, argumentándose que se trata de una práctica deleznable en la que no puede incurrir un Estado de Derecho ${ }^{47}$. Por de pronto, no sólo puede decirse que las medidas premiales están muy arraigadas en la historia

cuando se refiere a los conflictos armados internos. Véase: CASSESE, Antonio, Diritto Internazionale (Bologna, Il Mulino, 2006), pp. 127 ss.

${ }^{45}$ Bernasconi, Alessandro, La collaborazzione processuale. Incentivi, protezione e strumenti di garanzia a confronto con l'esperienza statunitense (Milano, Giuffrè, 1995), pp. 79 ss.; Musco, Enzo, Los colaboradores de la justicia entre el pentitismo y la calumnia: problemas y perspectivas (traducción de Sánchez, Virginia), en Revista Penal, 2 (1998), pp. 35 ss.

${ }^{46} \mathrm{El}$ artículo 416 bis del Código Penal italiano que tipifica el delito de asociación de tipo mafioso, se refiere expresamente a la "omertà".

${ }^{47}$ Villegas, Myrna, cit. (n. 6), p. 27. 
del Derecho penal, sino también, que las legislaciones de los Estados más democráticos contemplan medidas de esta naturaleza. Es indudable que tienen un carácter eminentemente utilitarista, pues en definitiva lo que pretende es prevenir delitos de especial gravedad "premiando" a quienes colaboran. Si la finalidad del Derecho penal es la prevención de delitos debe recurrir a instrumentos que tengan un menor costo social. Es preferible que el Estado renuncie a parte de la pena u otorgue beneficios - costo- si con ello previene futuros delitos -beneficio- . Por otra parte, no debe olvidarse que puede lograrse adicionalmente la reinserción de los arrepentidos o "pentiti".

\section{Bien jurídico.}

No pocos problemas se presentan en este orden, pues como es natural la calificación de conductas terroristas siempre la realizará quien se ha visto afectado por ella, es decir, el Estado. En cambio, quien ejecuta los actos no los va a estimar como tales. Por el contrario, siempre hallará argumentos para justificarlos. A ello se agregaría que los actos terroristas también pueden cometerlos agentes del Estado, por tanto, surgen dificultades para calificar las medidas de defensa que el pueblo puede adoptar ${ }^{48}$. Ello pone de manifiesto, que el término siempre tiene una connotación negativa, ningún grupo o persona se autocalificará de terrorista. Esa es la razón de que un concepto tan ambiguo como la guerra al terrorismo tenga tal fuerza retórica.

Sin pretender entrar en disquisiciones de esta naturaleza, que se comprenden más bien en el campo político, sí puede afirmarse que el terrorismo consiste, esencialmente, en el uso estratégico e indiscriminado de la violencia, procurando alguno de los fines más arriba indicados. Por cierto, no se trata de cualquier violencia, sino aquella que causa terror en la población, bajo la incertidumbre de que cualquier persona y en cualquier momento puede ser objeto de un ataque terrorista. Se infunde terror, pues la identidad de las víctimas es irrelevante, son sólo instrumentos para intimidar ${ }^{49}$

En este sentido, debe tenerse presente que estos actos tienen un componente simbólico que no se puede eludir ${ }^{50}$ : la especial vulnerabilidad que tiene lugar al cuestionarse estructuras esenciales que conforman el basamento de la identidad social, como son las formas de conveniencia y entendimiento democrático ${ }^{51}$. Independiente incluso, de si hay o no víctimas. Como muy

${ }^{48} \mathrm{Al}$ respecto, Bassiouni, Cherif M., cit. (n. 1), pp. 96 ss.

${ }^{49}$ Cancio Meliá, Manuel, cit. (n. 31), p. 404.

${ }^{50}$ Cancio Meliá, Manuel, cit. (n. 29), pp. 41-42.

${ }^{51}$ Sobre lo que debe entenderse por identidad en este contexto, véase: PAREdes CaStañón, José Manuel, El 'terrorista' ante el Derecho penal: por una política criminal intercultural, en Serrano-Piedecasas, José Ramón - Demetrio Crespo, Eduardo (directores), Terrorismo y Estado de Derecho (Madrid, Iustel, 2010), pp. 201 ss. 
bien lo expresa Canció Meliá, la especial peligrosidad de las organizaciones terroristas, se manifiesta en que más allá de las lesiones a los bienes jurídicos individuales, tiene lugar un ataque (ideal) al Estado. Pretenden ocupar un espacio normativo, en cuanto cuestionan el poder coercitivo del Estado ${ }^{52}$.

Pues bien, considerando lo expuesto precedentemente en cuanto a que se está frente a organizaciones que conforman una especial fuente de peligrosidad y que, por tanto, se justifica anticipar la protección de los bienes jurídicos relacionados con los delitos objeto de la organización, es que no se está frente a un único bien protegido. Por el contrario, el que se sancionen etapas previas pone de manifiesto que en estos casos se está frente a delitos de peligro $^{53}$, vinculados a determinados delitos de la parte especial, como pueden ser la vida, la integridad física, el patrimonio, la libertad personal ${ }^{54}$.

No cabría sostener pues que en estos casos se estaría frente a un bien jurídico único o determinado, esto es, que se configuraría la lesión a un bien jurídico colectivo ${ }^{55}$. Por de pronto, surge la dificultad de determinar cuál es. ¿Puede hablarse de la seguridad pública o paz pública? O incluso, ¿de seguridad del orden mundial? En este sentido, resulta extremadamente complejo poder precisar sus entornos - por cierto muy difusos- pues en estos casos desempeñan un papel particular los sentimientos colectivos ${ }^{56}$ -las llamadas sensaciones de inseguridad-, tan manipulable a los vaivenes políticos y a los medios de comunicación ${ }^{57}$. Además, argumentos de esta naturaleza pueden dar "carta blanca" a los Estados más poderosos para justificar sus actuaciones.

\section{Consideraciones finales.}

No es exagerado sostener que enfrentamos desafíos particularmente complejos. Y es que, por un lado, no estamos dispuestos como sociedad a

${ }^{52}$ Cancio Meliá, Manuel, cit. (n. 31), p. 400.

${ }^{53}$ Cancio Meliá, Manuel, cit. (n. 31), p. 390.

${ }^{54}$ Así, Viganò, Francesco, cit. (n. 9), p. 17.

${ }^{55} \mathrm{Al}$ respecto, Rosi, Elisabetta, cit. (n. 33), p. 157, tomando en cuenta el carácter transnacional de este tipo de organizaciones, representan un peligro para la comunidad mundial.

${ }^{56}$ Cancio Meliá, Manuel, cit. (n. 31), p. 394.

${ }^{57}$ Silva SÁnchez, Jesús María, cit. (n. 8), pp. 37 ss.; Brandariz García, José Ángel, Política criminal de la exclusión (Granada, Comares, 2007), pp. 65 ss.; ALBRECHT, Peter-Alexis, El Derecho penal en la intervención de la política populista, en Instituto de Ciencias Criminales de Frankfurt (editor) - Área de Derecho Penal de la Universidad Pompeu Fabra, La insostenible situación del Derecho Penal (traducción de Robles, Ricardo, Granada, Comares, 2000), p. 480-481; Garapon, Antoine, Juez y democracia (traducción de Escrivá, Manuel, Barcelona, Flor del Viento ediciones, 1997), pp. 110-111. 
renunciar a siglos de trabajo dirigidos a construir nuestro patrimonio garantístico. Pero, tampoco podemos olvidar que los peligros que representa el terrorismo de carácter global pueden alterar, quizás para siempre, nuestras formas de convivencia. Lamentablemente, tendremos que coexistir con este fenómeno, por lo que debemos buscar las mejores herramientas para enfrentarlo, sin caer desde luego en su juego, como sería actuar al margen de toda regla; es decir, la lógica de la guerra.

Al menos existe el consenso que estos desafíos los podemos enfrentar con las armas del Derecho penal y que éstas pueden ser eficaces. La cuestión es cómo lograr el debido equilibrio a través de la flexibilización de determinadas reglas, sin que, por otro lado, ello suponga exacerbar las medidas preventivas de orden policial o en propuestas puramente asegurativas -así, favorecer jurisdicciones militares-.

La tarea no es sencilla pero es irrenunciable. Como la planteó Lord Hoffman en la Cámara de los Lores cuando se discutió la ley antiterrorista británica en 2001: "I said that the power of detention is at present confined to foreigners and I would not like to give the impression that all that was necessary was to extend the power to United Kingdom citizens as well. In my opinion, such a power in any form is not compatible with our constitution. The real threat to the life of the nation, in the sense of a people living in accordance with its traditional laws and political values, comes not from terrorism but from laws such as these. That is the true measure of what terrorism may achieve. It is for Parliament to decide whether to give the terrorists such a victory"s8.

\section{LA TORTURA A SOSPECHOSOS POR AGENTES ESTATALES PARA SALVAR LA VIDA DE INOCENTES}

\section{Exposición del tema.}

El segundo punto a tratar es, por cierto, de particular complejidad y motivo de numerosas discusiones. Para graficar el problema, recurriré nuevamente al caso citado al inicio de este trabajo:

Se dio aviso de que está por estallar otra bomba nuclear en California. Los agentes federales torturan a sospechosos para saber dónde se encuentra. El tiempo apremia y se corre el riesgo de que mueran otras 12.000 personas o quizás más.

En lo inmediato, respecto de los agentes federales puede presentarse una colisión de deberes. Por una parte, tienen un deber de actuar ¿bajo que

\footnotetext{
${ }^{58}$ http: - - www.publications.parliament.uk - pa - ld200405 - ldjudgmt - jd041216 - a\&oth-6.htm (consultado el 25 de mayo de 2010). La cursiva es mía.
} 
reglas actúan? Por otro lado, tienen un deber de no torturar. Pues bien, qué sucedería si efectivamente tiene lugar la explosión de la bomba, por la cual mueren muchas personas, sin haber ejercido ningún apremio ilegítimo. $\mathrm{O}$, en su caso, sí torturaron a los sospechosos, pero la bomba nunca se detonó.

Por cierto, no se trata de un problema reciente, pues en Israel se viene discutiendo desde hace bastante tiempo -asos de las "ticking time bombs" ${ }^{59}$, ni tampoco estamos frente a hechos o situaciones respecto de las cuales la doctrina penal no se haya cuestionado, como son los conflictos que se presentan entre el deber de proteger la dignidad del autor y el de la víctima - por ejemplo, apremiar ilegítimamente al secuestrador para saber dónde está la persona (caso "Daschner" en Alemania ${ }^{60}$ ), o los cuestionamientos que surgen cuando las pruebas se han obtenido ilícitamente, pero demuestran la efectiva comisión del delito- . En definitiva, conflictos que surgen por los límites que se le impone al Estado en la persecución del delito.

Si bien las sociedades democráticas rechazan la práctica de la tortura, y

${ }^{59} \mathrm{Al}$ respecto, el Informe de la Comisión Landau de 1987 permitía bajo particulares circunstancias ciertas presiones físicas en los interrogatorios a terroristas peligrosos que representaban una grave amenaza para el Estado de Israel y para sus ciudadanos. Tales circunstancias apuntaban a obtener información de quien se suponía implicado personalmente en graves actividades terroristas para evitar un homicidio inminente. También a los casos en que el detenido estaba en posesión de una información decisiva sobre una organización terrorista y que no podía obtenerse de ninguna otra fuente. Ver, Comission of Inquiry into methods of investigation of the General Security Service regarding hostile terrorist activity en Israel Law Review, vol. 23, 2-3 (1989), pp. 146 ss.; ver también http: - - www.unhchr.ch - tbs - doc.nsf - (Symbol) - CAT.C.33. Add.2.Rev.1.Sp?OpenDocument (consultado el 25 de mayo de 2010). Sin embargo, cabe destacar que el Tribunal Supremo israelí en sentencia de 6 de septiembre de 1999 estimó que tales prácticas atentaban contra la dignidad humana. Sobre esta sentencia: Supreme Court of Israel, Judgment Concerning the Legality of the General Security Service's Interrogation Methods (September 6, 1999), en Levinson, Sanford (editor), Torture (New York, Oxford University Press, 2004), pp. 165 ss.; véanse: Амвоs, Kai, May a State Torture Suspects to Save the Life of Innocents? en Journal of International Criminal Justice, 6 (2008), p. 264; Molina Fernández, Fernando, La ponderación de intereses en situación de necesidad extrema: ¿es justificable la tortura? en CUERDA RiEzu, Antonio (director), La respuesta del Derecho penal ante los nuevos retos (Madrid, Dykinson, 2005), pp. 271-274. Para un análisis comparado entre la legislación alemana, israelí y paquistaní sobre la tortura: WeILERT, Anja Katarina, Grundlagen und Grenzen des Folterverbotes in verschiedenen Rechtskreisen (Berlin, Springer, 2009).

${ }^{60}$ Roxin, Claus, cit. (n. 25), pp. 23 ss.; Ambos, Kai, cit. (n. 59), pp. 262 ss. Cabe destacar, que con fecha 1 de junio de 2010, la Corte Europea de Derecho Humanos señaló que en este caso se violó el artículo 3 de la Convención europea de derechos humanos que prohíbe la tortura. En efecto, Magnus Gäfgen -el secuestrador- al ser interrogado por la policía fue objeto de torturas prohibidas por el citado artículo 3. Sentencia "case of Gäfgen v. Germany”, n. 22978 - 05. 
se descarta como práctica estatal respecto de los detenidos, sí han surgido voces que proponen su justificación bajo ciertas circunstancias. Es decir, manteniendo como regla general su prohibición, existirían contextos en que debe justificarse ${ }^{61}$.

En el pasado, la confesión del imputado tenía extrema importancia pues la búsqueda de la verdad histórica -principalmente en los orígenes del sistema inquisitivo- no sólo tenía como propósito la reconstrucción de hechos que se hallaban ocultos porque así lo quería el autor-obviamente no se reconocía la presunción de inocencia- , sino que además, se identificaba el delito con el pecado. No sólo interesaba determinar la ocurrencia de un hecho, sino también el pensamiento, la intimidad del sujeto. Era el inquisidor quien poseía la verdad, por tanto debían descorrerse los velos que la ocultaban, incluso a través de la tortura. Por tal razón la tortura adquirió tanta relevancia, pues era indispensable para lograr la confesión y así extraer la verdad. Por ello tuvo una minuciosa regulación -también como garantía para el imputado a fin de impedir apremios innecesarios-, para así lograr que la confesión estuviera dotada de la necesaria calidad que permitiera reconstruir la verdad histórica ${ }^{62}$.

Justamente, los acontecimientos del 11 de septiembre han generado importantes discusiones en este ámbito. Como se expuso precedentemente, en el pasado la tortura era una práctica regulada y aceptada, hoy no lo es, como lo ponen en evidencia diversas convenciones internacionales.

Puede decirse que existe una posición muy mayoritaria - por parte de la doctrina, no así de la opinión pública ${ }^{63}$ - que se decanta por prohibir la tortura y no admitir margen alguno de justificación. Sin embargo, la cuestión

${ }^{61}$ Dershowitz, Alan, Terrorismo (edición italiana, Roma, Carocci, 2003), p. 135 ss., aunque en un principio era más bien partidario de dar una disculpa, como se aprecia en Dershowitz, Alan, Is it Necessary to Apply 'Physical Pressure' to Terrorists - and to Lie About it? en Israel Law Review, 23 (1989) 2-3, pp. 192 ss.

${ }^{62}$ Roxin, Claus, Derecho procesal penal, (25a edición, alemana, traducción de Córdoba, Gabriela - Pastor, Daniel, Buenos Aires, Editores del Puerto, 2003), p. 558; Foucault, Michel, Vigilar y castigar (traducción de Garzón, Aureliano, Buenos Aires, Siglo XXI, 2002), pp. 43-44; Ferrajoli, Luigi, Derecho y razón. Teoria del garantismo penal (traducción de Andrés Ibáñez, Perfecto y otros, Madrid, Trotta, 1995), p. 565 , señala que tratándose de los procesos por crímenes de lesa majestad y los procesos eclesiásticos por los delitos de herejía y brujería, las torturas adquirieron mayor fuerza y dureza. Lo anterior pues el ofendido era Dios y por ello la acusación, obligatoria y pública, suponía una investigación de la verdad que no admitía incertidumbre, por tanto la colaboración del acusado debía ser forzosa.

${ }^{63}$ En el caso "Daschner" buena parte de la opinión pública era del parecer que la práctica de la policía se encontraba totalmente justificada; es decir, la tortura o la amenaza de ésta al secuestrador debía ser permitida sin con ello podía salvarse la vida del menor encerrado. Véase: Molina Fernández, Fernando, cit. (n. 59), p. 278. 
por resolver es si correspondería valorar el problema también en sede de culpabilidad, esto es, si cabe o no la configuración de una exculpación.

\section{Disposiciones sobre la tortura y qué se entiende por tal.}

Las normas que prohíben la tortura no sólo se encuentran en los Códigos penales y procesales penales, sino también en las constituciones y en convenciones internacionales. En el caso chileno, los artículo $150 \mathrm{~A}$ y $150 \mathrm{~B}$ del Código Penal se refieren a la aplicación de tormentos o apremios ilegitimos físicos o mentales a personas privadas de libertad, ya sea que lo practiquen funcionarios públicos o particulares. Por su parte, el Código Procesal Penal señala en el artículo 93 letra $\mathrm{H}$, dentro de los derechos del imputado, que éste no puede ser "sometido a tortura ni a otros tratos crueles, inhumanos o degradantes"; el artículo 195 dispone la prohibición de la tortura como "método de interrogación o de investigación”. Por su parte, la Constitución de la República, en su artículo 1 afirma que "las personas nacen libres e iguales en dignidady derechos" y el artículo 19, dentro de las garantías de la persona, "probibe la aplicación de todo apremio ilegitimo".

La Convención contra la tortura y otros tratos o penas crueles, inhumanos o degradantes, adoptada por la Asamblea General de la Organización de las Naciones Unidas, en su artículo 2 dispone lo siguiente: "1. Todo Estado Parte tomará medidas legislativas, administrativas, judiciales o de otra indole eficaces para impedir los actos de tortura en todo territorio que esté bajo su jurisdicción. 2. En ningún caso podrán invocarse circunstancias excepcionales tales como estado de guerra o amenaza de guerra, inestabilidad politica interna $o$ cualquier otra emergencia pública como justificación de la tortura. 3. No podrá invocarse una orden de un funcionario superior o de una autoridad pública como justificación de la tortura".

Como es de esperar otras legislaciones siguen el mismo derrotero. En el caso europeo, la Convención europea de derechos humanos de 1950, en su artículo 3 expresa que "nadie podrá ser sometido a tortura ni a penas o tratos inhumanos o degradantes". En el ordenamiento alemán, el artículo $1^{\circ}$ de la Ley fundamental señala que la " dignidad humana es inviolable" y el artículo 104 de la misma, apunta a que "las personas detenidas no podrán ser maltratadas ni psíquica ni físicamente”. El $§ 343$ del Código penal tudesco, al referirse a la obtención de declaración en un proceso, se prohíbe que se "maltrate a otro físicamente o de otra manera utilice contra él violencia, le amenace con violencia, o le atormente psíquicamente". Por último, la ley procesal penal del mismo país, en el $\$ 136$ a se refiere a la prohibición de determinados métodos para examinar al inculpado. España sigue una línea similar, pues su Constitución, en el artículo 15 prohíbe que una persona pueda ser "sometida a tortura ni a penas o tratos inhumanos o degradantes". Su Código Penal, en el 
título $7^{\circ}$ (artículo $173 \mathrm{ss}$.) tipifica como delito "la tortura y otros delitos contra la integridad moral". Por último, Italia también en su carta fundamental expresa claramente la prohibición de actos de "violencia física y moral sobre personas privadas de libertad" (artículo 13.4). El Código procesal penal de la nación itálica, en el artículo 188, también se afirma la "probibición de métodos o técnicas que puedan afectar la libertad de autodeterminación o alterar la capacidad de recordar y valorar los hechos". En todo caso, resulta curioso que en el Código criminal italiano no existan delitos expresos en esta materia, aplicándose los delitos comunes -lesiones, coacciones- agravados por la calidad de funcionario público. Lo expuesto ha generado una importante crítica de la doctrina, pues la inadecuada incriminación de la tortura supone un evidente incumplimiento de obligaciones internacionales ${ }^{64}$.

Teniendo en consideración que no se presentan mayores reparos en disponer la prohibición de la tortura, la cuestión es precisar qué entendemos por ella.

El artículo 1 de la Convención contra la tortura y otros tratos o penas crueles, inhumanas o degradantes, adoptada por la Asamblea General de la Organización de las Naciones Unidas señala: "Todo acto por el cual se inflija intencionadamente a una persona dolores o sufrimientos graves, ya sean físicoso mentales, con el fin de obtener de ella o de un tercero información o una confesión, de castigarla por un acto que haya cometido, o se sospeche que ha cometido, o de intimidar o coaccionar a esa persona o a otras, o por cualquier razón basada en cualquier tipo de discriminación, cuando dichos dolores o sufrimientos sean infligidos por un funcionario público u otra persona en el ejercicio de funciones públicas, a instigación suya, o con su consentimiento o aquiescencia. No se considerarán torturas los dolores o sufrimientos que sean consecuencia únicamente de sanciones legítimas, o que sean inherentes o incidentales a éstas".

Por su parte, el artículo 2 de la Convención Interamericana para prevenir y sancionar la tortura, adoptada el 9 de diciembre de 1985 por la Organización de los Estados Americanos dispone: "Se entenderá por tortura todo acto realizado internacionalmente por el cual se inflijan a una persona penas $o$ sufrimientos físicos o mentales, confines de investigación criminal, como medio intimidatorio, como castigo personal, como medida preventiva, como pena $o$ con cualquier otro fin. Se entenderá también como tortura la aplicación sobre una persona de métodos tendientes a anular la personalidad de la victima $o$ a disminuir su capacidad física o mental, aunque no causen dolor físico o angustia psíquica. No estarán comprendidos en el concepto de tortura las penas o sufrimientos físicos o mentales que sean únicamente consecuencia de medidas

${ }^{64} \mathrm{Al}$ respecto, Colella, Angela, C'è un giudice a Strasburgo, en Rivista Italiana di Diritto e Procedura Penale (2009), pp. 1801 ss. 
legales o inherentes a éstas, siempre que no incluyan la realización de los actos o la aplicación de los métodos a que se refiere el presente artículo".

Lo execrable de la tortura es que pone de manifiesto que la persona ya no es apreciada como sujeto de Derecho, sino, por el contrario, es considerado un objeto a merced de la fuerza estatal. Ya no tiene voluntad que expresar y por tanto, puede ser sometido a daños físicos y psíquicos -lo que incluye la amenaza de tortura, discutida en el caso "Daschner"- . En definitiva, se suprime todo atisbo de dignidad. Precisamente, la legitimidad en la actuación punitiva del Estado descansa en que considera al imputado -o siguiendo los mismos términos aquí empleados, al sospechoso-, un sujeto con voluntad y por tanto, lo considera como persona y no como mero instrumento ${ }^{65}$.

\section{3. ¿Esposible su justificación?}

Apreciado desde esta perspectiva, la respuesta puede ser una sola: no cabe bajo ninguna circunstancia su justificación. No obstante, hay quienes sostienen que en determinados casos -como el terrorismo- sí puede plantearse justificar la tortura, sobre la base de que el Estado no puede permanecer indiferente frente al acto agresivo y por tanto, debe ir a favor de las víctimas; es decir, frente a intereses contrapuestos, dignidad del sospechoso - quien ha creado el peligro- y dignidad de las víctimas, debe optarse por esta última. El infligir torturas en caso de conductas terroristas representaría un mal menor frente al mal mayor, como es la muerte de miles de personas y el miedo generalizado que ello provoca. En definitiva, el Estado no puede atarse de manos y aceptar ciertas reglas que llevarían al suicidio ${ }^{66}$.

${ }^{65}$ Parry, John T, Escalation and Necessity. Defining Torture at Home and Abroad, en Levinson, Sanford (editor), Torture (New York, Oxford University Press, 2004), p. 153; Hilgendorf, Eric, Folter im Rechtstaat? en Juristenzeitung (2004), p. 337; Greco, Luis, Las reglas detrás de la excepción. Reflexiones respecto de la tortura en los grupos de casos de las "ticking time bombs" (traducción de Riggi, Eduardo), en InDret, 4 (2007), pp. 13-14; disponible en www.indret.com (consultado el 27 de mayo de 2010); sobre lo acontecido en Chile bajo el gobierno de Pinochet, MATus, Jean Pierre, El informe Valech y la tortura masiva y sistemática como crimen contra la humanidad cometido en Chile durante el régimen militar, en Revista Electrónica de Ciencia Penal y Criminologia, 07 - 07 (2005), pp. 1 ss. (disponibe en http: - - criminet.ugr.es - recpc - 07 - recpc07.html. consultado el 27 de mayo de 2010).

${ }^{66} \mathrm{Al}$ respecto: GöTz, Heinrich, Das Urteil gengen Daschner im Lichte der Werteordnung des Grundgesetzes, en Neue Juristische Wochenschrift (2005), pp. 953 ss.; LEvinson, Sanford, 'Precommitment' and 'Postcommitment': The Ban on Torture in the Wake of September 11, en Texas Law Review, 81 (2003), pp. 243 ss., sosteniendo la necesidad de cruzar el Rubicón que representa la moral particular sobre el tema. Téngase presente el memorandum preparado por el fiscal general Alberto Gonzales para el gobierno de G. Bush, dirigido a justificar la tortura a sospechosos de terrorismo, BYBEE - Gonzales, Standard of Conduct for Interrogation, en GreEnBERG, Karen (editora), 
En esta línea Dershowitz señala: "I am against torture as a normative matter, and I would like to see its use minimized. I believe that at least moderate forms of non lethat tortured are in fact being used in the United States and some of its allies today. I think that if we ever confronted an actual case of inminent mass terrorism that could be prevented by the infliction of torture, we would use torture (even lethat torture) and public would be its use. I speak about this subject, I ask my audience for a show of hands on the empirical question "How many of you think that nonlethal torture would be used if we were ever confronted with a ticking bomb terrorist case?" Almost no one dissent from the view that torture would in fact be used, though there is widespread disagreement about whether it should be used. That is also my empirical conclusion. It is either true or false, and time will probably tell. I then present my conditional normative position, which is the central point of my chapter on torture" 67 .

Frente a lo expuesto, no cabe esgrimir tal ponderación de intereses. Es cierto, que si se observa desde una perspectiva, podríamos llamarla cuantitati$v a$ - esiones al torturado versus vida de de miles de personas- podría parecer razonable argumentar a favor de la justificación ${ }^{68}$. Sin embargo, lo que debe ponerse en la balanza es lo que representa la tortura como práctica estatal frente a la dignidad de la persona. Y es que valorándolo de esa perspectiva la tortura al sospechoso representaría el mal mayor. Al respecto, debe tenerse presente lo dispuesto en las convenciones contra la tortura anres citadas, las que son bastante claras en prohibirla, y que se ponen además en el contexto que aquí se examina, a saber, situaciones de guerra, amenazas de guerra o inestabilidades políticas. Es de sentido común pensar que quienes elaboraron estos instrumentos sí tenían en mente situaciones extremas - el riesgo de las bombas nucleares se conocía-. Detrás de todas estas normas, que también se expresan en los ordenamientos nacionales, se quiere dejar muy claro cuál es el límite del Estado: la dignidad humana es inviolable.

Como bien lo pone en evidencia Roxin: "Ciertamente se puede decir que el secuestrador ha vulnerado la dignidad humana de la víctima, al igual que hacen muchos delincuentes. Pero esto no legitima al Estado para atacar por su parte la dignidad humana del autor porque su superioridad moral frente al delincuente reside precisamente en que no utiliza los mismos medios que éste. Si al Estado le está prohibida toda vulneración de la dignidad humana y con ello también la tortura, entonces, lógicamente, no puede existir por su parte una vulneración de la dignidad humana en la omisión de medidas

The Torture Debate in America (New York, Cambridge Press, 2006), pp. 317 ss.

${ }^{67}$ Dershowitz, Alan, Torture Reasoning, en Levinson, Sanford (editor), Torture (New York: Oxford University Press, 2004), p. 266.

${ }^{68}$ Molina Fernández, Fernando, cit. (n. 59), p. 279. 
de tortura. Bien es verdad que el Estado está obligado a proteger la vida y la dignidad humana de sus ciudadanos en la medida de lo posible. Pero sólo en la medida de lo posible: la protección puede ser otorgada siempre sólo dentro de los límites establecidos a la actuación del Estado de Derecho. Entre estos límites se encuentra en primer lugar la prohibición de torturar" ${ }^{69}$.

Justificar la tortura, aún en casos excepcionales, llevaría a sostener que se trata de una actividad socialmente aceptada. Por tanto, concluir que bajo ciertos eventos se puede conculcar, violar la dignidad de una persona ${ }^{70}$. Como ya se señaló, la tortura anula toda forma de expresión del sujeto, que es donde descansa, precisamente, la legitimidad de la actuación estatal. Al afirmar que en algunos casos se justifica la tortura, se está señalando que para ese caso la voluntad del sujeto no tiene valor alguno, se lo cosifica ${ }^{71}$.

Es más, de justificarse la tortura se estaría frente a un nuevo paradigma, y es que el peligro ya no provendría del poder omnipresente del Estado -y que ha dado lugar a toda una construcción garantística- sino de las conductas que pueden desplegar los particulare ${ }^{72}$. Ya no debe observarse al Estado con desconfianza, por el contrario las amenazas provendrían de determinadas agrupaciones criminales. Por tanto, es preciso dotar al Estado de herramientas -como sería justificar la tortura en determinadas circunstancias- para enfrentar los peligros que pueden generar los particulares. En definitiva, el nuevo paradigma apuntaría a que se estaría frente a un Estado bueno hacia sus ciudadanos del que nada se debe temer. No cabe duda que se abre una puerta peligrosa.

\section{4. ¿Cabe la exculpación?}

Habiendo llegado a la conclusión de que bajo ninguna circunstancia se puede justificar; es decir, siempre la tortura estará prohibida, cabe preguntarse a continuación, ¿̇se puede exculpar?

Creo que en estos casos y bajo circunstancias muy estrictas sí puede plantearse la configuración de un supuesto de exclusión de la culpabilidad ${ }^{73}$. Estimarlo desde esta perspectiva deja muy claro y sin lugar a dudas que la

${ }^{69}$ Roxin, Claus, cit. (n. 25), p. 29. Molina Fernández, Fernando, cit. (n. 59), p. 281, señala además que la justificación de la tortura ofrece una valiosa oportunidad, precisamente, a quienes ataca. Los casos de Guantánamo y Abu Grahib no sólo no han ayudado a combatir el terrorismo, sino que además ha desprestigiado el accionar de quienes luchan en su contra.

${ }^{70}$ Амвоs, Kai, cit. (n. 59), p. 284.

${ }^{71}$ Greco, Luis, cit. (n. 65), p. 15.

${ }^{72}$ Greco, Luis, cit. (n. 65), p. 20.

${ }^{73}$ Así también lo sostienen, Roxın, Claus, cit. (n. 25), pp. 31-33; Амвоs, Kai, cit. (n. 59), pp. 285-286; Robinson, Paul, Letter to the Editor, en Israel Law Review, 23 1989) 2-3, p. 191. 
tortura será siempre una conducta ilícita; es decir, es un acto injusto. Empero, concurriendo determinados supuestos sí podría disculparse. Ahora bien y suscribiendo las palabras de Ambos -quien también participa de esta posición-, para evitar malentendidos es necesario considerar que se está frente a agentes estatales que tienen perfecto conocimiento de que se está frente a actos prohibidos y que corren el riesgo de ser sancionados ${ }^{74}$. Por tanto, se está frente a ciertos eventos que deben considerarse caso a caso. En este sentido, debe valorarse cuán inminente es el riesgo a enfrentar y excepcional el caso para los agentes estatales, que los "determinó" a torturar. Si para los agentes, conforme a su valoración de los hechos, era el único medio para poder evitar las consecuencias lesivas -en este caso, la explosión de la bomba- , podría exculparse. En este sentido, tampoco puede descartarse en el obrar del agente el natural instinto de autoconservación -él e incluso su familia también morirán-. Por el contrario, si el agente sabía que podía disponer de otros medios, no corresponde exculpar.

Para este mismo contexto, Roxin sostiene que puede plantearse una exculpación supralegal, respecto de quien en casos particularmente extremos ha torturado, pues "puede resultar absurdo el castigo del que salva infringiendo la prohibición"75. Para ello, recurre a los argumentos expuestos para los casos de estado de necesidad supralegal tratándose de las llamadas comunidades de peligro $^{76}$. Por ejemplo, un avión de caza derriba a un avión de pasajeros que se dirige a un edificio -como parece haber sucedido con uno de los aviones el 11 de septiembre de 2001-. Se salvan quienes ocupan el edificio, pero mueren los pasajeros del avión ${ }^{77}$. En ambos casos, se vulneraría una prohibición - no torturar y no matar-, pero por otro lado, actúan bajo el convencimiento que

${ }^{74}$ Aмвоs, Kai, cit. (n. 59), p. 286.

${ }^{75}$ Roxin, Claus, cit. (n. 25), p. 32.

${ }^{76}$ Roxin, Claus, Derecho Penal. Parte General (traducción de Luzón, Diego - Díaz y García, Miguel - De Vicente, Javier, Madrid, Civitas, 1997), I, pp. 961 ss.

${ }^{77}$ Politoff, Sergio, Obediencia y delito en contextos cambiantes, en De FiguereDo Dias, Jorge - Serrano Gómez, Alfonso - Politoff Lifschitz, Sergio y otros (directores), El penalista liberal. Homenaje a Manuel de Rivacoba y Rivacoba (Buenos Aires, Hammurabi, 2004), p. 531, sostiene que en estos casos se está frente a un estado de necesidad exculpante. Cabe destacar que la "Ley de seguridad aérea" alemana (Luftsicherheitgesetz), de enero de 2005, contemplaba en el párrafo 14.3 la posibilidad de recurrir a las fuerzas armadas para derribar un avión dirigido a atentar contra vidas humanas. Se autorizaba tal medida si era el único medio para salvar dichas vidas. Es del caso, que el Tribunal Constitucional alemán, en sentencia de 15 de febrero de 2006, declaró inconstitucional tal autorización por considerarla contraria a la dignidad humana y al derecho a la vida, en el entendido que el Estado no puede ordenar matar a personas inocentes. Ver la sentencia en http: - - www.bundesverfassungsgericht.de - entscheidungen - rs20060215_1bvr035705.html (consultado el 28 de mayo de 2010). 
es el único y muy excepcional camino que les permitiría salvar vidas. Si bien es cierto - afirma Roxin- la ley debe ser clara, precisa e inflexible en cuanto a la prohibición de la tortura, tampoco la justicia puede tener un "corazón de piedra" y en estos casos puede ser indulgente ${ }^{78}$.

Ahora bien, ¿qué sucede si luego la bomba no explosiona? o se aprecia que sí existían otros medios para lograr el objetivo propuesto sin tener que recurrir a la tortura, o bien, no se trataba del sospechoso. Obviamente son todas circunstancias que se conocen posteriormente -consideraciones ex post-. Es decir, al momento de actuar el agente estatal lo hace motivado por determinadas circunstancias concomitantes que lo compelen en una dirección. La pregunta es: ¿el error en la apreciación es o no relevante? Si estas situaciones de anormalidad motivacional pueden siempre excluir la culpabilidad, o aún estando presente, permitirían el castigo pero con un pena menor.

Según Roxin en estos casos de suposición errónea sobre los presupuestos objetivos o materiales de exclusión supralegal de responsabilidad han de ser tratados por analogía con el $₫ 35$ II del Código penal alemán ${ }^{79}$; esto es, si el error pudo evitarse se le castigará con una pena atenuada. Es decir, el tratamiento de un error de prohibición ${ }^{80}$.

Creo que en estos casos si el error ha determinado al sujeto y es de tal magnitud que afecta seriamente las condiciones motivacionales no cabe más que excluir la responsabilidad penal ${ }^{81}$. $\mathrm{Al}$ respecto, debe tenerse presente que esta esfera lo que afirma la culpabilidad, y en su caso la exculpación, son cuestiones eminentemente personales - queda clara y sin cuestionamientos la ilicitud del hecho-. El sujeto actúa voluntariamente, sabe que se trata de un acto prohibido - más aún en estos casos, ya que se trata de agentes estatales-, pero, precisamente, son ciertas circunstancias concomitantes de tal significación que han erosionado la motivación del sujeto frente a la norma, independientemente que sean o no ciertas tales circunstancias. El Derecho no desconoce aquello y por tal razón no le exige que actúe conforme a la norma prohibitiva.

De lo expuesto puede apreciarse que todas son consideraciones de orden fáctico, es decir, el agente no yerra sobre el derecho, pues conoce el significado jurídico de su actuar -dada su calidad de agente del Estado sabe que es un comportamiento prohibido-. Empero, sí puede argumentarse una

${ }^{78}$ Roxin, Claus, cit. (n. 25), p. 33.

${ }^{79}$ Roxin, Claus, cit. (n. 76), p. 962.

${ }^{80}$ De la misma opinión, Cury Urzúa, Enrique, Derecho Penal. Parte General (7 ${ }^{\mathrm{a}}$ edición, Santiago, Ediciones Universidad Católica de Chile, 2005), pp. 452-453.

${ }^{81}$ En este sentido, Mir Puig, Santiago, Derecho penal. Parte General (7 $7^{\mathrm{a}}$ edición, Barcelona, Reppertor, 2004), pp. 599-600; Fiandaca, Giovanni - Musco, Enzo, Diritto penale. Parte generale ( $4^{a}$ edición, Bologna, Zanichelli, 2004), p. 369. 
valoración errónea de cuestiones fácticas. Por tanto, no puede plantearse, según se señaló supra, como un caso propiamente de error de prohibición. En cambio, sí podría discutirse aplicar las mismas argumentaciones que respecto de una justificación putativa, esto es, la teoría moderada de la culpabilidad. El agente de haber sido más cuidadoso en su obrar habría podido interpretar de mejor forma las circunstancias concomitantes y con ello haber evitado la aplicación de la tortura. En consecuencia, castigar culposamente aquellos casos de error evitable ${ }^{82}$.

No puede desconocerse que estos son temas particularmente difíciles de abordar y muy sensibles, sobre todo en países como los nuestros, donde el tema de la tortura forma parte del pasado más oscuro. No obstante, no puede eludirse, pues hoy han adquirido especial actualidad.

[Recibido el 1 de julio y aceptado el 5 de noviembre de 2010].

\section{BiBLIOGRAFÍA}

Albrecht, Peter-Alexis, El Derecho penal en la intervención de la politica populista, en Instituto de Ciencias Criminales de Frankfurt (editor) - Área de Derecho Penal de la Universidad Pompeu Fabra, La insostenible situación del Derecho Penal (traducción de Robles, Ricardo, Granada, Comares, 2000).

Albrecht, Peter-Alexis, Krieg gegen den Terror". Konsequenzen für ein rechtstaaliches Strafrecht en Zeitschrift für die gesamte Strafrechtswissenschaft (2005).

Амвоs, Kai, May a State Torture Suspects to Save the Life of Innocents? en Journal of International Criminal Justice, 6 (2008).

Aponte, Alejandro, Derechopenal de enemigo vs Derecho penal del ciudadano. El Derecho Penal de emergencia en Colombia: entre la paz y la guerra, en Revista de Derecho de la Universidad Católica del Norte. Sede Coquimbo, 8 (2001).

ARNOLD, Roberta, The ICC as a New Instrument for Repressing Terrorism (Ardsley, New York, Transnational Publishers, 2004).

Bassiouni, Cherif M., Strumenti giuridiciper il contrasto del terrorismo internazionale: un'analisi di carattere politico, en BAssiounI, Cherif M. (editor), La cooperazione

${ }^{82}$ Politoff, Sergio - Matus, Jean Pierre - Ramírez, María Cecilia, Lecciones de Derecho Penal chileno. Parte General (2 ${ }^{a}$ edición, Santiago, Editorial Jurídica de Chile, 2004), pp. 348-349: "Puede suponerse, con todo, que el miedo haya sido insuperable, atendida la representación de los hechos por el sujeto, pero evitable. Es decir, si éste hubiera podido, en obedecimiento a un deber de cuidado, reaccionar menos precipitadamente, es concebible -ya que se trata de u n error fáctico- que se optara por una solución análoga a la que proponíamos para la justificación putativa: reconocer que "al error imprudente del hechor siga el castigo por el correspondiente hecho culposo". Mutatis mutandi, una solución análoga habría de darse al caso en que la fuerza que compele al autor fuese imaginaria, como el que actúa bajo el poder de un engaño intimidatorio”. 
internazionale per la prevenzione e la repressione della criminalitá organizata e del terrorismo (Milano, Giuffrè, 2005).

BAuccio, Luca, L'accertamento del fatto reato di terrorismo internazionale. Aspetti teorici epratici (Milano, Giuffrè, 2005).

Beccaria, Cesare, Dei delitti e delle pene (edición a cargo de Franco Ventura, Torino, Giulio Einaudi, 1981).

BERGALLI, Roberto, Libertad y seguridad: un equilibrio extraviado en la modernidad tardía, en Losano, Mario - MuÑoz Conde, Francisco, El Derecho ante la globalización y el terrorismo (Valencia, Tirant lo Blanch, 2004).

BERNASCONI, Alessandro, La collaborazzione processuale. Incentivi, protezione estrumenti di garanzia a confronto con l'esperienza statunitense (Milano, Giuffrè, 1995).

Brandariz García, José Ángel, Politica criminal de la exclusión (Granada, Comares, 2007).

Bybee - Gonzales, Standard of Conduct for Interrogation, en Greenberg, Karen (editor), The Torture Debate in America (New York, Cambridge Press, 2006).

Cancio Meliá, Manuel - Gómez-Jara Díez, Carlos (coordinadores), Derechopenal del enemigo. El discurso penal de la exclusión (Buenos Aires-Montevideo, Edisofer, $\mathrm{B}$ de $\mathrm{F}, 2006$ ).

Cancio Meliá, Manuel, Derecho penal del enemigo y delitos de terrorismo, en Revista de Derecho Penal Contemporáneo, 3 (2003).

Cancio Meliá, Manuel, Sentido y límites de los delitos de terrorismo, en SerranoPiedecasas, José Ramón - Demetrio Crespo, Eduardo (directores), Terrorismo y Estado de Derecho (Madrid, Iustel, 2010).

Cano Paños, Miguel Ángel, Perfiles de autor del terrorismo islamista en Europa en Revista Electrónica de Ciencia Penal y Criminología, 11-07 (2009).

CARella, Gabriella, Nominalismo e lotta al terrorismo internazionale: il caso delle extraordinary renditions, en Venturini, Gabriella - Bariatti, Stefania (editores), Diritti individuali e giustizia internazionale. Liber Fausto Pocar (Milano, Giuffrè, 2009).

Carnevali, Raúl, Derecho penal como ultima ratio. Hacia una politica criminal racional, en CARnevali, Raúl, Problemas de politica criminaly otros estudios (Santiago, LegalPublishing, 2009).

Carrara, Francesco, Programa de Derecho criminal. Parte General (traducción de Ortega Torres, José y Guerrero, Jorge, Bogotá, Temis, 1985).

Cassese, Antonio, Diritto Internazionale (Bologna, Il Mulino, 2006).

Colella, Angela, C'è un giudice a Strasburgo, en Rivista Italiana di Diritto e Procedura Penale (2009).

Comission of Inquiry into Methods of Investigation of the General Security Service Regarding Hostile Terrorist Activity en Israel Law Review, 23 (1989) 2-3.

Cury Urzúa, Enrique, Derecho Penal. Parte General ( $7^{\text {a }}$ edición, Santiago, Ediciones Universidad Católica de Chile, 2005).

Dershowitz, Alan, Is it Necessary to Apply 'Physical Pressure' to terrorists - and to Lie About it? en Israel Law Review. 23 (1989) 2-3.

Dershowitz, Alan, Terrorismo (edición Italiana, Roma, Carocci, 2003).

Dershowitz, Alan, Torture Reasoning, en Levinson, Sanford (editor), Torture (New York, Oxford University Press, 2004).

Dolcini, Emilio - Marinucci, Giorgio (editor), Codice Penale commentato (2a edición, Milano, Ipsoa, 2006). 
Douglas, Roger, Proscribing Terrorist Organizations: Legislation and Practice in five English-Speaking en Criminal Law Journal, 32 (2008).

Etcheberry, Alfredo, Derecho penal ( $3^{a}$ edición, Santiago, Editorial Jurídica de Chile, 1998).

Feijoó Sánchez, Bernardo, El Derecho penal del enemigo y el Estado democrático de derecho, en Revista de Derecho Penal Contemporáneo 16 (2006).

Ferrajoli, Luigi, Derecho y razón. Teoria del garantismo penal (traducción de Andrés Ibáñez, Perfecto y otros, Madrid, Trotta, 1995).

Fiandaca, Giovanni - Musco, Enzo, Diritto penale. Parte generale (4a edición, Bologna, Zanichelli, 2004).

FORNASARI, Gabriele (editor), Le strategie di contrasto alla criminalitá organizzata. Nella prospettiva di Diritto comparato (Padova, Cedam, 2002).

Foucault, Michel, Vigilary castigar (traducción de Garzón, Aureliano, Buenos Aires, Siglo XXI, 2002).

GARAPON, Antoine, Juez y democracia (traducción de Escrivá, Manuel, Barcelona, Flor del Viento Ediciones, 1997).

GöTz, Heinrich, Das Urteil gengen Daschner im Lichte der Werteordnung des Grundgesetzes, en Neue Juristische Wochenschrift (2005).

Gracia Martín, Luis, El horizonte del finalismo y el "Derecho penal del enemigo" (Valencia, Tirant lo Blanch, 2005).

GRECO, Luis, Las reglas detrás de la excepción. Reflexiones respecto de la tortura en los grupos de casos de las "ticking time bombs", traducción de Riggi, Eduardo, en InDret, 4 (2007).

Grosso, Carlo Federico, Le fattispecie associative: problemi dommatici e dipolitica criminale, en Moccia, Sergio (editor), Criminalità organizzata e risposte ordinamentali (Napoli, Edizioni Scientifiche Italiane, 1999).

Hassemer, Winfried, Fundamentos del Derecho penal (traducción de Muñoz Conde, Francisco - Arroyo Zapatero, Luis, Barcelona, Bosch, 1984).

Hilgendorf, Eric, Folter im Rechtstaat? en Juristenzeitung (2004).

Hirsch, Hans Joachim, Problemas actuales de la legislación penal propia de un Estado de Derecho, traducción de Guzmán, José Luis, en De Figueredo Dias, Jorge Serrano Gómez, Alfonso - Politoff Lifschitz, Sergio y otros (directores), El penalista liberal. Homenaje a Manuel de Rivacoba y Rivacoba (Buenos Aires, Hammurabi, 2004).

Hobbes, Thomas, Leviatán (traducción de Escahotado, Antonio, Madrid, ed. Nacional, 1979).

Jakobs, Günther - Cancio Meliá, Manuel, Derecho penal del enemigo (Madrid, Civitas, 2003).

JaковS, Günther, Criminalización en el estadio previo a la lesión de un bien jurídico en Jakoвs, Günther, Estudios de Derecho penal (traducción de Peñaranda, Enrique, Madrid, Civitas, 1997).

JаковS, Günther, La autocomprensión de la Ciencia del Derecho penal ante los desafíos del presente en Eser, Albin - HAsSEMER, Winfried - BurkHARdT, Björn (coordinador de la versión alemana); MUÑoz ConDE, Francisco (coordinador de la versión española), La ciencia del Derecho penal ante el nuevo milenio (traducción de Manso, Teresa Valencia, Tirant lo Blanch, 2004).

Jiménez de AsúA, Luis, Un comentario a la anunciada acción penal internacional en Revista de Ciencias Penales, 10-12 (1944). 
KANT, Emmanuel, Sobre la paz perpetua (7ª edición, traducción de Abellán, Joaquín, Madrid, Tecnos, 2005).

Levinson, Sanford, 'Precommitment' and 'Postcommitment': The Ban on Torture in the Wake of September 11, en Texas Law Review, 81 (2003).

Manzini, Vincenzo, Tratado de Derechopenal (traducción de Sentís Melendo, Buenos Aires, Ediar, 1948).

MarinucCi, Giorgio - Dolcini, Emilio, Derecho penal 'mínimo' y nuevas formas de criminalidad (traducción de Carnevali, Raúl), en Revista de Derecho de la Universidad Católica del Norte. Sede Coquimbo, 8 (2001).

Matus, Jean Pierre, El informe Valech y la tortura masiva y sistemática como crimen contra la humanidad cometido en Chile durante el régimen militar, en Revista Electrónica de Ciencia Penal y Criminología, 07 - 07 (2005).

Militello, Vincenzo - Paoli, Letizia - ARnold, Jörg (editores), Il crimine organizzato come fenomeno transnazionale. Forme di manifestazione, prevenzione e repressione in Italia, Germania e Spagna (Freiburg, Ed. Iuscrim, Max Planck Institut, 2000).

Mir Puig, Santiago, Derecho penal. Parte General ( $7^{\mathrm{a}}$ edición, Barcelona, Reppertor, 2004).

Moccia, Sergio (editor), Criminalità organizzata e risposte ordinamentali (Napoli, Edizioni Scientifiche Italiane, 1999).

Molina Fernández, Fernando, La ponderación de intereses en situación de necesidad extrema: ¿es justificable la tortura? en CUERDA RIEZU, Antonio (director), La respuesta del Derecho penal ante los nuevos retos (Madrid, Dykinson, 2005).

Muñoz Conde, Francisco, De nuevo sobre el "Derecho penal del enemigo" (Buenos Aires, Hammurabi, 2005).

Muñoz Conde, Francisco, Presente y futuro de la Dogmática jurídico-penal, en Revista Penal, 5 (2000).

Musco, Enzo, Los colaboradores de la justicia entre el pentitismo y la calumnia:problemas y perspectivas, traducción de Sánchez, Virginia, en Revista Penal, 2 (1998).

NARDUCCI, Giuseppe, Nella differenza tra atti terroristici ed eversivi i confini del "nuovo" reato, Diritto e giustizia, 3 (2002).

Parano, Carola - Centonze, Alessandro (editor), L'attività di contrasto alla criminalità organizzata (Milano, Giuffrè, 2005).

Paredes Castañón, José Manuel, El 'terrorista' ante el Derecho penal: por una política criminal intercultural, en Serrano-Piedecasas, José Ramón - Demetrio CresPO, Eduardo (directores), Terrorismo y Estado de Derecho (Madrid, Iustel, 2010).

PARry, John T, Escalation and Necessity. Defining Torture at Home and Abroad, en LEvinson, Sanford (editor), Torture (New York, Oxford University Press, 2004).

Patalano, Vincenzo (editor), Nuove strategieper la lotta al crimine organizzato transnazionale (Torino, Giappichelli, 2003).

Pérez Cepeda, Ana Isabel, Definición del delito de terrorismo como un delito internacional, en Serrano-Piedecasas, José Ramón - Demetrio Crespo, Eduardo (directores), Terrorismo y Estado de Derecho (Madrid, Iustel), 2010).

Picchio Forlati, Maria Laura (editor), Controllo degli armamenti elotta al terrorismo tra Nazione Unite, Nato e Unione Europea (Padova, Cedam, 2007).

Pistorelli, Luca, Punito anche il solo arruolamento, en Guida al Diritto, 33 (2005).

Politoff, Sergio - Matus, Jean Pierre - Ramírez, María Cecilia, Lecciones de Dere- 
cho Penal chileno. Parte General (2a edición, Santiago, Editorial Jurídica de Chile, 2004).

Politoff, Sergio, Obediencia y delito en contextos cambiantes, en De Figueredo

Dias, Jorge - Serrano Gómez, Alfonso - Politoff Lifschitz, Sergio y otros (directores), Elpenalista liberal. Homenaje a Manuel de Rivacoba y Rivacoba (Buenos Aires, Hammurabi, 2004).

Quintero Olivares, Gonzalo, Adonde va el Derechopenal. Reflexiones sobre las Leyes Penales y los penalistas españoles (Madrid, Civitas, 2004).

Reiteano, Simona, Le misure di contrasto al terrorismo internazionale tra Unione Europea e normativa italiana di adattamento, en L'Indice Penale (2004).

Robinson, Paul, Letter to the Editor, en Israel Law Review, 23 (1989) 2-3.

Rosi, Elisabetta, Terrorismo internazionale: le nuove norme interne di prevenzione e repressione. Profili di diritto penale sostanziale, en Diritto Penale e Processo, 1 (2002).

Roxin, Claus, ¿Puede admitirse o al menos quedar impune la tortura estatal en casos excepcionales? (traducción de Gómez Navajas, Justa), en Cuadernos de Política Criminal, 83 (2004).

Roxin, Claus, Derecho Penal, Parte General, T. I (traducción de Luzón, Diego - Díaz y García, Miguel - De Vicente, Javier, Madrid, Civitas, 1997).

Roxin, Claus, Derecho procesal penal (25ª edición alemana, traducción de Córdoba, Gabriela - Pastor, Daniel, Buenos Aires, Editores del Puerto, 2003).

Schünemann, Bernd, Consideraciones críticas sobre la situación espiritual de la ciencia jurídico-penal alemana (Bogotá, Universidad Externado de Colombia, 1996).

Silva SÁnchez, Jesús María, Aproximación al Derechopenal contemporáneo (Barcelona, Bosch, 1992).

Silva Sánchez, Jesús María, Eficiencia y Derecho penal, en Anuario de Derecho penal $y$ Ciencias Penales (1996).

Silva SÁnchez, Jesús María, La “intervención a través de organización” ¿una forma moderna de participación en el delito? en Dolcini, Emilio - Paliero, Carlo Enrico (editores), Studi in onore di Giorgio Marinucci (Milano, Giuffrè, 2006), II.

Silva Sánchez, Jesús María, La expansión del Derechopenal. Aspectos depolitica criminal en las sociedades postindustriales (2a edición, Madrid, Civitas, 2001).

Silva SÁnchez, Jesús María, Los principios inspiradores de las propuestas de un Derecho penal europeo. Una aproximación critica, en Revista Penal, 13 (2004).

Silva Sánchez, Jesús María, Retos cientificos y retos politicos de la ciencia del Derecho penal, en Revista de Derecho Penal y Criminología, 9 (2002).

SotTiaux, Stefan, Terrorism and the Limitation of Rights. The ECHR and US Constitution (Oxford and Portland, Oregon, Hart Publishing, 2008).

Supreme Court of Israel, Judgment Concerning the Legality of the General Security Service's Interrogation Methods (September 6, 1999), en Levinson, Sanford (editor), Torture (New York, Oxford University Press, 2004).

Susan, Herman N. - Finkelman, Paul (editor), Terrorism, Goverment, and Law. National Authority and Local Autonomy in the War on Terror (Westport, Connecticut, Praeger Security International, 2008).

Valsecchi, Alfio, Brevi osservazioni di Diritto penale sostanziale, en Diritto Penale e Processo, 10 (2005).

Valsecchi, Alfio, Il problema della definizione di terrorismo, en Rivista Italiana di Diritto e Procedura Penale (2004). 
VERVAELE, John, La legislazione anti-terrorismo negli Stati Uniti. Inter arma silent leges? en Rivista Italiana di Diritto e Procedura Penale (2005).

VIganò, Francesco, La lucha contra el terrorismo de matriz islámica a través del Derecho penal: la experiencia italiana, traducción de Londoño, Fernando, en Politica Criminal, 3, A3 (2007).

Villegas, Myrna, Los delitos de terrorismo en el Anteproyecto de Código Penal en Politica Criminal, 2, A3 (2006).

WeIlert, Anja Katarina, Grundlagen und Grenzen des Folterverbotes in verschiedenen Rechtskreisen (Berlin, Springer, 2009).

Zaffaroni, Eugenio, El enemigo en el Derecho penal (Madrid, Dykinson, 2006).

Zaffaroni, Eugenio, Il crimine organizzato: una categoria fallita en Moccia, Sergio (editor), Criminalità organizzata e risposte ordinamentali (Napoli, Edizioni Scientifiche Italiane, 1999). 